This is the final peer-reviewed accepted manuscript of:

Atsuko Namiki, Eleonora Rivalta, Heiko Woith, Thomas R. Walter, Sloshing of a bubbly magma reservoir as a mechanism of triggered eruptions, Journal of Volcanology and Geothermal Research, Volume 320, 15 June 2016, Pages 156-171.

The final published version is available online at: https://doi.org/10.1016/j.jvolgeores.2016.03.010

Rights / License:

The terms and conditions for the reuse of this version of the manuscript are specified in the publishing policy. For all terms of use and more information see the publisher's website.

This item was downloaded from IRIS Università di Bologna (https://cris.unibo.it/)

When citing, please refer to the published version. 


\title{
Sloshing of a bubbly magma reservoir as a mechanism of triggered eruptions
}

\author{
Atsuko Namiki*a, Eleonora Rivalta ${ }^{\mathrm{b}}$, Heiko Woith ${ }^{\mathrm{b}}$, Thomas R. Walter ${ }^{\mathrm{b}}$ \\ ${ }^{a}$ Environmental Sciences, Graduate School of Integrated Arts and Sciences, Hiroshima \\ University, 1-7-1, Kagamiyama, Higashi Hiroshima, Hiroshima 739-8521, JAPAN \\ ${ }^{b}$ Helmholtz Centre Potsdam, GFZ German Research centre for Geosciences, Telegrafenberg, \\ 14473 Potsdam, GERMANY
}

\begin{abstract}
Large earthquakes sometimes activate volcanoes both in the near field as well as in the far field. One possible explanation is that shaking may increase the mobility of the volcanic gases stored in magma reservoirs and conduits. Here experimentally and theoretically we investigate how sloshing, the oscillatory motion of fluids contained in a shaking tank, may affect the presence and stability of bubbles and foams, with important implications for magma conduits and reservoirs. We adopt this concept from engineering: severe earthquakes are known to induce sloshing and damage petroleum tanks. Sloshing occurs in a partially filled tank or a fully filled tank with density-stratified fluids. These conditions are met at open summit conduits or at sealed magma reservoirs where a bubbly magma layer overlays a newly injected denser magma layer. We conducted sloshing experiments by shaking a rectangular tank partially filled with liquids, bubbly fluids (foams) and fully filled with density-stratified fluids; i.e., a foam layer overlying a liquid layer. In experiments with foams, we find that foam collapse occurs for oscillations near the resonance frequency of the fluid layer. Low viscosity and large bubble size favor foam collapse during sloshing. In the layered case, the collapsed foam mixes with the underlying liquid layer. Based on scaling considerations, we constrain the conditions for the oc-
\end{abstract}

\footnotetext{
*Corresponding author: tel:+81-82-424-6461, fax + 81-82-424-0758

Email address: namiki@hiroshima-u.ac.jp (Atsuko Namiki*)
} 
currence of foam collapse in natural magma reservoirs. We find that seismic waves with lower frequencies $<1 \mathrm{~Hz}$, usually excited by large earthquakes, can resonate with magma reservoirs whose width is $>0.5 \mathrm{~m}$. Strong ground motion $>0.1 \mathrm{~m} \mathrm{~s}^{-1}$ can excite sloshing with sufficient amplitude to collapse a magma foam in an open conduit or a foam overlying basaltic magma in a closed magma reservoir. The gas released from the collapsed foam may infiltrate the rock or diffuse through pores, enhancing heat transfer, or may generate a gas slug to cause a magmatic eruption. The overturn in the magma reservoir provides new nucleation sites which may help to prepare a following/delayed eruption. Mt. Fuji erupted 49 days after the large Hoei earthquake (1707) both dacitic and basaltic magmas. The eruption might have been triggered by magma mixing through sloshing.

Keywords: large earthquake, foam collapse, magma mixing, outgassing

\section{Introduction}

An increasing number of observations have shown that volcanic eruptions can be triggered by earthquakes (e.g., Yokoyama, 1971; Nakamura, 1975; Linde and Sacks, 1998; Hill et al., 2002; Manga and Brodsky, 2006; Walter and Amelung, 2007; Eggert and Walter, 2009; Watt et al., 2009). Earthquakes may also trigger milder types of volcanic activity, for example they may enhance the heat flux at active volcanoes (Harris and Ripepe, 2007; Donne et al., 2010), increase the seismicity rate in geothermal or volcanic areas (e.g., Hill et al., 1993; Linde et al., 1994; Brodsky and Prejean, 2005; West et al., 2005), reduce the seismic velocity of crustal rocks (Battaglia et al., 2012; Brenguier et al., 2014), or cause unusual degassing (Cigolini et al., 2007; Walter et al., 2009). After the 2011 Tohoku-Oki $M_{\mathrm{w}}=9.0$ earthquake, triggered earthquakes, sudden changes of seismicity rate and subsidence were observed in volcanic areas throughout Japan (Yukutake et al., 2011; Fujita et al., 2013; Takada and Fukushima, 2013).

Earthquakes activate volcanoes through static and dynamic stress variations (e.g., Marzocchi et al., 2002; Manga and Brodsky, 2006; Walter, 2007). Static 
stress changes due to earthquakes originate from the permanent displacement of faults. Static stress changes decay rapidly as $r^{-3}$ with the distance from the hypocenter, r, (Hill and Prejean, 2007). Stress changes may involve volumetric expansions (Walter and Amelung, 2007; Watt et al., 2009), decompressing magma reservoirs and conduits, which in turn encourages bubble nucleation and growth, potentially leading to eruptions. Static stress changes last long-term and may explain time-delayed triggering of volcanic activity at a regional distance (Marzocchi, 2002; Watt et al., 2009; Chesley et al., 2012; Bonali, 2013; Bonali et al., 2013), and may even control the locations of magma rise by pressure localization (Nostro et al., 1998; Walter and Amelung, 2006).

Dynamic stress changes are originated by seismic waves and can affect volcanoes at greater distances, as they decay as $r^{-2}$ or $r^{-3 / 2}$ for body or surface waves, respectively (Hill and Prejean, 2007). Large earthquakes are usually originated by the rupture of long faults, thus the seismic waves include long-periodic components. Long-period ground motion attenuates slowly with distance, potentially affecting widespread areas (Koketsu and Miyake, 2008). Low frequency waves are more effective at triggering than short-period waves of comparable amplitude (Brodsky and Prejean, 2005).

Based on increasing evidence of volcanic unrest triggered by distant earthquakes (e.g., Linde and Sacks, 1998; Cannata et al., 2010), several mechanisms have been proposed (e.g., Hill et al., 2002). Seismicity may favor gas bubble nucleation and growth in magmas, as experimentally shown for ground water (Crews and Cooper, 2014). Dynamic stressing may change permeability and pore pressure, which can enhance ground water mobility (e.g., Woith et al., 2003; Elkhoury et al., 2006; Manga et al., 2012; Candela et al., 2014; Hurwitz et al., 2014). Shear deformation by seismic waves may induce liquefaction of crystalline mush (Sumita and Manga, 2008). Ascending bubbles over a long distance in a sealed magma reservoir may increase reservoir pressure (e.g., Steinberg et al., 1989; Sahagian and Proussevitch, 1992; Pyle and Pyle, 1995). Earthquakes seem advancing the occurrence of eruptions of volcanoes which are ready to erupt (Bebbington and Marzocchi, 2011). 
Here, we propose that oscillation of magma contained in conduits or reservoirs may be another potential mechanism to trigger a volcanic eruption. This mechanism is adopted from engineering sciences, where petroleum tanks may be damaged by mass oscillations of the liquid inside the tank, a mechanism known as sloshing (e.g., Ohta and Zama, 2005; Hatayama, 2008; Faltinsen and Timokha, 2009). Sloshing has been studied mainly to prevent damage on liquid tanks mounted on moving vehicles (e.g., Housner, 1957, 1963; Faltinsen and Timokha, 2009; Rebouillat and Liksonov, 2010), but similarly applies also to earthquakes (e.g., Ohta and Zama, 2005). In volcanic systems, sloshing in the Overlook crater lava lake at Kilauea excited by rockfalls has been observed by visual and seismic records (Dawson and Chouet, 2014). Transient outgassing bursts and weak explosive eruptions have also been observed after the rockfall events (Carey et al., 2013; Orr et al., 2013).

In general, sloshing occurs in a partially filled tank, because the fluid needs free space to move (e.g., Popov et al., 1992; Winkler, 2000; Romero et al., 2006; Thiagarajan et al., 2011). Thus, this mechanism is directly applicable to open conduit volcanic systems or a lava lake. If a magma reservoir has a layered structure, however, we hypothesize that one layer can behave as a relatively mobile space when the density and compressibility contrasts between the two layers are sufficiently large. A foam layer overlying a dense melt layer in a closed magma reservoir meets this condition. If sloshing occurs inside a magma reservoir, the surface (interface) of the magma(s) will be strained. The bubbles in the flowing magma may become interconnected so that the gas inside the bubbles can separate from the surrounding melt and escape as volcanic gases or large bubbles (Namiki, 2012; Okumura et al., 2013). Furthermore, magma deformation by sloshing may cause magma mixing through overturn, recognized as an important process to trigger eruptions (e.g., Sparks et al., 1977; Pallister et al., 1992; Viccaro et al., 2006). Here, oscillation of a layered system made of a low viscosity foam and a liquid layer has been investigated, in which an overlying foam layer does not significantly affect the resonance frequency of the lower liquid layer during oscillations, but reduces the amplitude of the interface 
(Bronfort and Caps, 2012; Sauret et al., 2015). However, it is still unknown how sloshing deforms bubbles in a viscous foam layer, which in turn affects the gas separation from the surrounding liquid.

In this paper, we present laboratory simulations in order to better understand the sloshing of a magma reservoir. We shake a fluid-filled tank horizontally by using a shaking table. We vary the oscillation parameters (amplitude of horizontal displacement $A$ and frequency $f$ ) and the fluid properties inside the tank (one and two layer fluids with varying thickness ratio, viscosity, bubble volume fraction, and solid particle fraction). Our experiments show that, under certain conditions, the bubbles inside the oscillating tank collapse and the fluids overturn. After describing our observations, we present an analytical model characterizing the foam collapse conditions, and apply our scaling to find parameter ranges of foam collapse in geologic situations. At the end, we discuss the 1707 eruption of Mt. Fuji as a potential application of the sloshing model.

\section{Sloshing terminology and parameters}

We simulate the oscillation of a magma reservoir (magma chamber or volcanic conduit) by shaking a tank filled with viscous fluids on a shaking table (Figure 1). When the tank undergoes externally forced oscillations, the fluid inside the tank moves. In the following, we call this fluid motion "sway" which has same meaning of "slosh". We thus call the amplitude of the surface undulation as "sway amplitude $(\xi)$ " instead of "slosh amplitude" to avoid confusion with amplitude of horizontal displacement $(A)$. Notations are summarized in Table 1 .

Housner $(1957,1963)$ summarized the analytical approaches of sloshing by assessing the balance of forces. If a mass $M$ is located inside an oscillating tank undergoing a displacement of $A \sin (\omega t)$, the force acting on the mass is $-M A \omega^{2} \sin (\omega t)$, where $\omega=2 \pi f$ is the angular frequency, and $t$ is the time. In a two dimensional tank with a fluid thickness $h$, if a wave forms on the fluid surface with a wave length of $\lambda$, the mass of the fluid in the wave becomes 
$M \sim \rho \lambda h$. We thus approximate the maximum force acting on a fluid parcel as $\rho \lambda h A \omega^{2}$ (Figure 1).

The dispersion law of an inviscid fluid inside an oscillating rectangular tank with small sway amplitude is obtained by assuming the potential flow (e.g., Faltinsen and Timokha, 2009),

$$
\omega=\sqrt{k g \tanh (h k)}=\sqrt{g \frac{\pi n}{l} \tanh \left(h \frac{\pi n}{l}\right)},
$$

where $k=2 \pi / \lambda$ is the wave number and $n=1,2, \ldots$ We note that Eq.(1) is based on a linear approximation for small amplitude and an inviscid fluid. However, it is empirically known that Eq.(1) frequently explains experiments with large sway amplitudes and viscous fluids (e.g., Faltinsen and Timokha, 2009; Sauret et al., 2015). We also verify its validity in our experiments. We thus use this dispersion law.

When the frequency of the tank oscillation overlaps with the natural modes of the fluid inside the tank, the fluid motion resonates. Swaying excites standing waves and amplifies the fluid surface. Eq.(1) indicates that the natural modes for the sway depend mainly on the tank shape and the liquid thickness (e.g., Faltinsen and Timokha, 2009).

Here, we consider a fundamental mode of sloshing in which $\lambda / 2 \sim l$, where $l$ is the width of the tank, and calculate resonance frequency as

$$
f_{\mathrm{r}}=\frac{1}{2 \pi} \sqrt{\frac{\pi g}{l} \tanh \left(\frac{\pi h}{l}\right)} .
$$

In Eq.(2), when the fluid layer is sufficiently thin $(h \ll l), \tanh (\pi h / l) \sim \pi h / l$ so that the resonance frequency depends on fluid thickness as $f_{\mathrm{r}} \sim \sqrt{g h} /(2 l)$. On the other hand, for a thick fluid layer $(h \gg l), \tanh (\pi h / l) \sim 1$, so that the resonance frequency is determined by the width of the tank only, $f_{\mathrm{r}} \sim$ $1 /(2 \pi) \sqrt{\pi g / l}$.

Similarly, the wave propagation velocity, $c=\omega / k$, depends on the fluid layer thickness. For a sufficiently thin layer, $h \ll \lambda$,

$$
c=\sqrt{g h} .
$$


Contrary, when the liquid layer is sufficiently thick, $h \gg \lambda$,

$$
c=\sqrt{\frac{g}{k}} .
$$

In most of our experiments, the fluid fills more than half of the tank width $(h>l / 2)$, so that the resonance frequency becomes $f_{\mathrm{r}}>1.73 \mathrm{~Hz}$, resulting in resonance frequencies around $f_{\mathrm{r}} \sim 1.8 \mathrm{~Hz}$, and that for mode $2, f \sim 2.5 \mathrm{~Hz}$.

\section{Methods}

\subsection{The shaking apparatus}

We use a shaking table (GeoSIG GSK-166) at GFZ Potsdam to impose horizontal oscillations on our fluid tank with a displacement $A \sin (\omega t)$ (Figure 1). The displacement amplitude $A$ and the angular frequency $\omega$ are changed independently. For a fixed value of displacement amplitude $A$, we increase $\omega$ step by step, then increase $A$ and conduct the experiments with the same sequence of frequencies. Our experiments are conducted close to the upper-limit loading of the shaking table $A \omega^{2}<1 g$, where $g=9.8 \mathrm{~m} \mathrm{~s}^{-2}$. As a result, we cannot explore cases where both amplitude and frequency of shaking are large, simultaneously.

During the shaking, we measure acceleration rates and find that $A \omega^{2}$ represents the maximum measured acceleration rate (the detailed waveform of acceleration depends on the location of the sensor). We thus use the theoretically calculated acceleration rate to interpret our experiments and do not further discuss the detailed waveform.

The sway of the fluids in the tank is monitored by means of two cameras. One is a high speed camera (CASIO EXILIM EX-ZR700) with a resolution of $512 \times 384$ at 240 frames per second (fps). This camera is fixed to the shaking table. The other is high vision digital video camera (SONY HDR-XR150) with a resolution of $1920 \times 1080$ at $30 \mathrm{fps}$, fixed to the ground. 


\subsection{The magma and magma reservoir analogue}

We use glucose syrup solutions as a magma analogue. By varying the water content of the syrup solution, we change its viscosity from $0.1 \mathrm{~Pa} \mathrm{~s}$ to $90 \mathrm{~Pa} \mathrm{~s}$, which overlaps with the viscosity of basaltic melt and sub-solidus basaltic magma with low crystal fraction, in the range $1-10^{4} \mathrm{~Pa} \mathrm{~s}$ (e.g., Ishibashi, 2009; Vona et al., 2011; Lev et al., 2012). The surface tension of syrup solutions is estimated as similar to that of water, $0.07 \mathrm{~N} \mathrm{~m}^{-1}$, and similar to those of silicate melt 0.01-0.1 $\mathrm{N} \mathrm{m}^{-1}$ (e.g., Bagdassarov et al., 2000; Mangan and Sisson, 2005). The density of the bubble-free syrup is approximately $\rho=1400 \mathrm{~kg} \mathrm{~m}^{-3}$.

We introduce bubbles in the syrup by a chemical reaction of baking soda and citric acid, following Namiki (2012). The bubble volume fraction, $\phi_{\mathrm{b}}$, defined as the ratio of the total volume of bubbles to the total volume of the bubbly fluid, is controlled by the amount of chemicals and varied in the range of $0 \leq$ $\phi_{\mathrm{b}} \leq 0.95$. The bubble radius varies with aging within $0.2 \leq R \leq 5 \mathrm{~mm}$. We do not include volatile exsolution in our experiments during sloshing because of technical difficulties, but discuss briefly its role in the implication section.

As an analogue of crystals in magma, we introduce plastic particles with irregular shapes. The density of particles is $1500 \mathrm{~kg} \mathrm{~m}^{-3}$, and their size is 0.4 $0.6 \mathrm{~mm}$. The volume fraction of particles, $\phi_{\mathrm{p}}$, defined as the ratio between volumes of particles and bubble-free liquid, which is consistent with the definition used for crystallinity of pumice and scoria, varied in the range of $0 \leq \phi_{\mathrm{p}} \leq 0.31$.

We model rigid-wall magma reservoirs by a sealed acrylic tank with a rectangular shape whose dimensions of height, width, and breadth are $0.24,0.24$, and $0.09 \mathrm{~m}$, respectively (Figure 1). The tank is sealed with a lid and experiments with different filling level can simulate the different geometries; i.e., the partially filled tank simulates open conduits and the fully filled tank corresponds to closed-conduit or reservoirs. The tank is filled with one or two layers of fluids.

We vary the thickness of the fluid layers $(h)$, the liquid viscosity $(\eta)$, and the bubble $\left(\phi_{\mathrm{b}}\right)$ and particle volume fractions $\left(\phi_{\mathrm{p}}\right)$. The experimental conditions are classified into 3 groups: 
1. One liquid layer (later labeled with the symbol $\times$ ),

2. One foam layer without particles $(\bigcirc)$ and with particles $(\diamond)$,

3. A two-layer system where a foam without particles overlies a liquid layer $(\triangle)$ and a foam with particles overlies a liquid layer $(\star)$.

We also vary the oscillation properties of horizontal displacement $(A)$ and frequency $(f)$. In total, we shake the tank under 1167 different conditions. Shaking duration is 10 seconds under each condition in most of experiments. The experimental conditions are summarized in Table 2, 3 and in Figure 2.

\section{Description of experiments}

\subsection{Experiments with one liquid layer}

In this section we describe the basic behavior of sloshing by showing the one liquid layer experiments (Figures 3, 4, and supplementary video 1, 2), which are consistent with previous works (e.g., Faltinsen and Timokha, 2009). We varied the liquid viscosity $(0.1-14 \mathrm{~Pa} \mathrm{~s})$, the liquid layer thickness $(0.015-0.24 \mathrm{~m})$, the frequency $(0.2-6 \mathrm{~Hz})$, and the amplitude of the horizontal displacement (3-140 mm), see Table 3a.

\subsubsection{Responses to displacement amplitudes and frequencies}

Figures 3 shows the response of the liquid layer to different displacement amplitudes and frequencies. During the shaking, the surface of the liquid layer sways; i.e., a surface wave appears. As the shaking proceeds, the swaying amplitude increases and reaches a steady-state within 2-3 oscillations. In Figures 3 and 4 , we show the undulation of the liquid surface when the surface undulation becomes the maximum at the left side, after the swaying has reached the steady-state.

The swaying amplitude under steady-state increases with the tank oscillation frequency, $f$, and displacement amplitude, $A$ (Figure 3). However, we observe that after increasing the oscillation frequency to a value as high as $6 \mathrm{~Hz}$ with $A=5 \mathrm{~mm}$, the amplitude and the wave length of the sway become smaller 
again. This occurs because the imposed frequency is much larger than the resonance frequency of the tank fluid at the fundamental mode, $f_{\mathrm{r}}=1.8 \mathrm{~Hz}$. The frequency of $6 \mathrm{~Hz}$ is close to the higher mode of $n=11$, according to Eq.(1).

\subsubsection{Thickness effect}

The vertical column in Figure 4 shows that the behavior of the liquid layer in an oscillating tank strongly depends on the thickness of the liquid layer $(h)$. When $h$ is small, the swaying amplitude is also small (Figure 4, bottom). We observe the same phenomena in the range of frequency of $0.5-2 \mathrm{~Hz}$.

When a sealed tank is almost full of fluid, the sway amplitude is negligible as shown by two small bubbles located at the top of the tank surrounded by the blue circle. Those change their shapes but do not migrate (Figure 4, top). The figure also illustrates heterogeneously dispersed particles in the tank that do not get rearranged. This is because fluids need a free space to originate sloshing (e.g., Popov et al., 1992; Winkler, 2000; Romero et al., 2006; Thiagarajan et al., 2011).

\subsubsection{Viscosity effect}

The horizontal row in Figure 4 shows the viscosity dependence. The swaying amplitude of the fluid surface becomes small for larger fluid viscosities (Figure 4, right). In contrast when the viscosity is low enough, the surface wave breaks (Figure 4, left).

\subsection{Experiments with one foam layer}

In the one foam layer experiments, we vary the foam parameters, i.e., layer thickness, bubble volume fraction and liquid viscosity, in addition to the oscillation parameters, i.e., displacement amplitude $A$ and frequency $f$ (see Table $3 \mathrm{~b}$ ). We observe foam collapse in experiments with a high bubble volume fraction $\left(\phi_{\mathrm{b}}=0.79\right)$ oscillating with a large displacement amplitude $(A \geq 20 \mathrm{~mm})$ and frequency range of $2<f<3 \mathrm{~Hz}$ (Figure 5) which is close to the resonance frequency $f \sim f_{\mathrm{r}}$. 
Figure 5 and supplementary video 3 summarize the sequence of experiments in which foam collapse is observed. Figure 5a shows that the response of the foam layer $\left(\phi_{\mathrm{b}}=0.79\right)$ depends on $A$ and $f$. With $A=10 \mathrm{~mm}$, the surface fluctuations are very small for $f=2 \mathrm{~Hz}$ and still small for $f=3 \mathrm{~Hz}$ (Figure $5 \mathrm{a}$, left column). However, $A=20 \mathrm{~mm}$ and $f=3 \mathrm{~Hz}$ lead to a foam collapse (Figure 5a, middle column). After oscillating with a larger amplitude of $A=$ $30 \mathrm{~mm}$, the foam volume reduces to less than half of the initial value (Figure 5a, right column). Figure 5b is a time evolution of foam height, and shows that, when the imposed frequency exceeds the resonance frequency of $f_{\mathrm{r}}=1.8$, the foam height begins decreasing.

Other experiments show the conditions preventing foam collapse (Table $3 \mathrm{~b}$ ). When a sealed tank is full $(h=0.24 \mathrm{~m})$, the oscillation does not affect the foam. This is consistent with the experiments with a full tank of liquid (Figure 4). When the liquid viscosity is large, the foam volume decreases less than in experiments with a less viscous liquid (Figure 5). A foam layer with small bubbles and with a lower bubble volume fraction does not collapse. We thus infer that a smaller bubble size, lower bubble fraction, and larger viscosity also prevent foam collapse. The effect of the particles is unclear.

\subsection{Experiments with two layers \\ 4.3.1. Foam collapse}

The experiments described above show that fluids in a fully filled tank do not move and that in such cases the foam does not collapse. Yet, if there exists a layered structure defined by density contrast in the tank, the interface between the liquid and the foam layer can slosh. This is what we observed in a series of experiments with foams overlying liquid layers (Table 3c).

An example is shown in Figure 6a1-a4 and supplementary video 4, in which the displacement amplitudes and frequencies are increased in a stepwise fashion similar to the experiments with one foam layer (Figure 5). The sway amplitudes increase for larger displacement amplitudes and frequencies around $f \sim f_{\mathrm{r}}$. This is consistent with the one liquid layer experiments (Figure 3). For instance, the 
deformation of the interface is small at the displacement amplitude of $A=$ $3 \mathrm{~mm}$ and $10 \mathrm{~mm}$ (Figure 6a1,2), but becomes large at $A=20 \mathrm{~mm}$ for the same frequency of $f=2 \mathrm{~Hz}$, resulting in the collapse of most of the foam (Figure 6a3). For $f=3 \mathrm{~Hz}$, the remnants of the foam, including small bubbles and particles, mix with the liquid in the lower layer. The remnants of the foam can be recognized as dark regions in the pictures (Figure 6a4). Some parts of the remnants stick against the tank wall.

The sequence of the foam collapse is observed in Figure 6b1. The bright region in the foam indicates that the foam has collapsed in that region. The foam collapse begins at $A=10 \mathrm{~mm}$. The remnant of the foam mixes with the liquid in the lower layer at frequencies of $f>2 \mathrm{~Hz}$.

The flow velocity in the lower liquid layer of these experiments are presented in Figure 7a1-a4. The velocity is calculated by particle image velocimetry, which is an image-matching method widely used to extract shape, deformation, and motion measurements (Sutton et al., 2009). The method has been applied to many laboratory experiments (Sutton et al., 2009) and terrestrial photogrammetric problems (Walter, 2011). We defined squared subsets of $(2 n+1) \times(2 n+1)$ pixels, selected values were large enough to contain a distinctive intensity pattern but small enough to achieve a sub-pixel level of accuracy, and calculated the 2-dimensional offsets of the correlation peaks in two subsequent images. Results are displayed in an image vector format together with contour maps, and show the fluid velocity. Note that gray regions do not always show the representative flow velocity inside the foam. For instance, when the foam is opaque and the bubbles adhering to the tank wall do not move, the calculated velocity is quite low even if inside the foam is flowing. Similarly, the calculated velocity for a homogeneous fluid does not represent the flow velocity. In general, the calculated velocity is faster for larger displacement amplitudes and frequencies, suggesting that a rapid and large deformation of the liquid layer contributes to the foam collapse. 


\subsubsection{After the foam collapse}

Figure 6a5-a8 and b2 show the results of oscillations after the foam collapse. Similar to Figure 6a1-a4, the deformation amplitude of the interface becomes larger for larger displacement amplitude. When $A=20 \mathrm{~mm}$ and $f=2 \mathrm{~Hz}$, which is close to the resonance frequency of the liquid layer, the mixing (dark) region is restricted to the right and left sides of the tank, because the surface wave is a steady wave at this frequency so that the vertical flow of the liquid is localized. In contrast, for $f=3 \mathrm{~Hz}$, the surface wave becomes a progressive wave and mixing occurs in the entire layer. Figure $6 \mathrm{~b} 2$ shows that mixing reaches the deeper part of the reservoir.

The calculated flow velocity for these experiments are shown in Figure 7a5a8. Similar to Figure 7a1-a4, the flow velocity becomes faster for larger displacement amplitudes and frequencies. The velocity around the interface is almost the same as when the foam is present under the same displacement amplitude and frequencies. We thus conclude that the existence of a foam does not affect the liquid flow significantly.

By varying some of the experimental conditions in other series of experiments (Table 3c), we gathered that when the liquid viscosity of the foam becomes larger and the bubble size is smaller, the foam collapse becomes difficult. This result is consistent with that of a single foam layer.

\section{Summary of experimental results}

Our experimental results show that a foam can collapse during sloshing and remnant of the collapsed foam mixes with the underlying liquid layer. If these phenomena occur in a real magma reservoir, one might speculate that the foam collapse can release volcanic gasses and trigger volcanic activities. The collapsed foam mixing with the underlying liquid can supply nucleation sites to prepare subsequent eruptions.

In order to apply our experimental results to real magma reservoirs, we have to describe our experimental results with non-dimensional numbers which 
are applicable to the real magma reservoirs. We infer that foam collapse has two requirements 1) deformation of the whole foam layer, and 2) rupture of the individual bubble films. This is because foam collapse occurs in our experiments when sway amplitude is large and large bubbles are surrounded by low-viscosity liquids.

We thus first derive a scaling law explaining the sway amplitudes and test it with our experimental results in Section 5.1. Next, we introduce two nondimensional numbers in Sections 5.2.1 and 5.2.2. Using two non-dimensional numbers, we make a regime diagram showing the conditions for foam collapse and test it with our experimental results in Section 5.2.3.

\subsection{A scaling law for the sway amplitude}

\subsubsection{Sway amplitude of liquid layers}

Our experiments showed that the sway amplitude depends on the imposed frequency, displacement amplitude, fluid thickness, and viscosity. This is consistent with previous works (e.g., Faltinsen and Timokha, 2009). In order to derive the scaling law, first we consider the frequency dependence and then incorporate other parameters.

Figure 8 summarizes the frequency dependence of the sway amplitude measured for liquid layer experiments with respect to the normalized frequency $f / f_{\mathrm{r}}$. The maximum sway amplitude is observed when the imposed frequency is around the resonance frequency. This is consistent with the widely known fact that resonance excites the fluid motion. Figure 8 also indicates that the dispersion law shown in Eq.(1) for an inviscid fluid and small sway amplitudes is valid in our experiments with large viscosity liquid and sway amplitudes similarly to experiments with a low viscosity foam (Sauret et al., 2015).

The sway amplitude is measured from the recorded video of the experiments. When the sway does not reach the roof of the tank, we measured the sway amplitudes by averaging the upward and downward deformation of the surface. In other cases, we measured the amplitude from the downward deformation of the surface. 
Here, our interest is in large sway amplitudes to originating foam collapse. We thus focus on experiments with $f / f_{\mathrm{r}}<1.2$ in the following.

Next, we consider the effect of other parameters. A horizontal oscillation, $x=A \sin (\omega t)$, originates both vertical and horizontal flow velocities and rises the fluid surface vertically $(\zeta)$, while viscous dissipation tends to decrease the sway amplitude. From the energy balance with a viscous damping parameter derived by Keulegan (1959), we obtained an empirical equation to explain the measured sway amplitude excited by imposed sinusoidal oscillation of the tank (Appendix A),

$$
\zeta \sim \frac{A \omega^{2} \sqrt{h}}{g\left(\sqrt{\frac{\eta}{\rho^{*} \omega}}\right)^{1 / 2}} \frac{(\lambda / 2)}{2 \pi},
$$

where $\rho^{*}=\rho$ is the density of oscillating layer, and we use $\lambda \sim 2 l$. Note, $\sqrt{\frac{\eta}{\rho \omega}}$ is a length scale of viscous dissipation (e.g., Keulegan, 1959; Landau and Lifshitz, 1987), so that Eq.(5) consists of ratios of accelerations and square root of length scales.

We test Eq.(5) in Figure 9. The cross and plus symbols indicate experiments conducted with a liquid layer. Figure 9 shows that crosses and pluses are plotted on the black line. Here, the relative position of the camera with respect to the fluid surface originates an uncertainty, so our measurements include an error of a factor of about two. Therefore, we interpret Figure 9 as that the amplitudes of the surface waves as calculated by Eq.(5) reproduce well the measured amplitude in the experiments with one liquid layer.

Here, we only plot experiments with $f / f_{\mathrm{r}}<1.2$, whose frequencies are not significantly larger than the resonance frequency, because Eq.(5) does not take into account the decreasing sway amplitude for $f / f_{\mathrm{r}}>1.2$ as shown in Figure 8. Figure 9 also does not include experiments with small top space $(<30 \mathrm{~mm})$, whose sway amplitudes are affected by the lack of space at the top.

\subsubsection{Sway amplitude of foam layers}

In order to estimate the sway amplitude of a foam layer by using Eq.(5), we should take into account the bubble fraction dependence on the physical 
properties of foams. As a representative density, for one foam layer experiments, the averaged foam density $\rho^{*}=\rho\left(1-\phi_{\mathrm{b}}\right)$ may be appropriate. For two layer experiments, the density difference between the liquid layer and the foam layer may affect the sway amplitude, we thus assume $\rho^{*}=\rho \phi_{\mathrm{b}}$. The viscosity of bubbly fluid depends on shear rate. Without an estimate of the sway amplitude, we cannot obtain shear rate as well as foam viscosity. Here, the foam viscosity varies within one order of magnitude, and can be scaled with liquid viscosity, (e.g., Mader et al., 2013). We thus use liquid viscosity as a reference. In Eq.(5), the sway amplitude is not sensitive to density and viscosity, $\zeta \propto\left(\rho^{*} / \eta\right)^{(1 / 4)}$. An error of one order of magnitude in the estimate of viscosity or density results in an error in the estimate of sway amplitude less than a factor of two.

Calculated sway amplitudes are plotted in Figure 9, solid circles, diamonds, triangles, and stars indicate experiments with a foam layer. For two layer experiments the y-axis shows the measured fluctuation of the interface. The measured fluctuations are smaller than the predictions.

This discrepancy may be related to the opacity of the foam. In our three dimensional experiments, we only can observe the deformation of opaque foam close to the tank wall, and may underestimate the deformation. An alternative explanation is that, for the two layer experiments, foam deformation needs an extra force which is not included in Eq.(5). Indeed, it has been reported that a thick foam layer overlying a low viscosity layer $\left(\eta \sim 10^{-3} \mathrm{~Pa} s\right)$ in a quasi-two dimensional tank reduces the sway amplitude (Sauret et al., 2015). Here, the bubbles close to the tank walls have had a significant impact on the damping of sloshing. In contrast, our experiments are conducted in a three dimensional tank.

In order to identify the source of this discrepancy, we calculate the flow velocity in Figure 7, and find that the flow velocity around the interface does not show a clear dependence on the existence of the foam. This result suggests that the measured sway amplitude around the wall is smaller than that inside the tank. We also note that the deformed foam can collapse before reaching the estimated sway amplitude and use the energy. We thus conclude that Eq.(5) 
explains some trends of sway amplitude. In Figure 9, the effect of particles is not obvious.

\subsection{Non-dimensional foam collapse conditions}

\subsubsection{Strain of a foam layer}

First, we consider the strain of a foam layer as a non-dimensional parameter. This idea is based on previous shear deformation experiments (e.g., Namiki, 2012; Okumura et al., 2013). Under shear deformation, foam collapse occurs when the strain in the foam exceeds a critical value.

The strain originating in a foam by sway can be calculated as:

$$
\frac{\zeta}{h_{\mathrm{f}}}
$$

where $h_{\mathrm{f}}$ is the thickness of the foam; i.e., $h_{\mathrm{f}}=h$ for the one layer foam experiments, and $h_{\mathrm{f}}=h_{\text {upper }}$ for two layer experiments. Here we use $\zeta$ defined in Eq.(5), so that Eq.(6) for foams will be a maximum estimate.

\subsubsection{Non-dimensional bubble strength}

Next, we consider non-dimensional number describing the deformation of a distinct bubble. In order to deform bubbles, the inertia force acting on each bubble originated by the oscillations should exceed the viscous resistance.

If an isolated bubble is surrounded by a uniform fluid, the inertia force $\left(\mathrm{F}_{\mathrm{i}}\right)$ acting on the bubble during a sinusoidal oscillation can be written as (e.g., Housner, 1957):

$$
\mathrm{F}_{\mathrm{i}}=\Delta \rho A \omega^{2}\left(\frac{4}{3} \pi R^{3}\right),
$$

where $R$ is the bubble radius, $A \omega^{2}$ is the acceleration, and $\Delta \rho$ is the density difference between the fluid and gas inside the bubble. We here assume that a homogeneous foam surrounds each bubble, so that $\Delta \rho=\rho\left(1-\phi_{\mathrm{b}}\right)$.

The viscous force $\left(\mathrm{F}_{\mathrm{v}}\right)$ to deform the membrane surrounding a bubble can be written as:

$$
\mathrm{F}_{\mathrm{v}}=\eta_{\mathrm{f}} \omega \delta R,
$$


where $\eta_{\mathrm{f}}$ is the viscosity of the liquid surrounding the bubbles, $\delta$ is the thickness of the membrane surrounding the bubble with a length scale of a bubble size. Assuming that bubbles of the same size are distributed uniformly in the foam, $\delta$ is estimated as

$$
\delta=R\left(\frac{1}{\phi_{\mathrm{b}}^{1 / 3}}-1\right) .
$$

The ratio of these two forces becomes:

$$
\frac{\mathrm{F}_{\mathrm{i}}}{\mathrm{F}_{\mathrm{v}}}=\frac{\frac{4}{3} \pi \Delta \rho A \omega R}{\eta_{\mathrm{f}}\left(\phi_{\mathrm{b}}^{-1 / 3}-1\right)}
$$

Eq.(10) indicates that a foam with larger bubbles and a larger bubble volume fraction in a less viscous liquid collapses more easily.

\subsubsection{Regime diagram}

We here test two non-dimensional numbers described in Eq.(6) and Eq.(10) with our experimental results. We plot the occurrence of foam collapse in Figure 10 using these two non-dimensional numbers. When the foam thickness decreases more than approximately $5 \mathrm{~mm}$ after the shaking, we classify the experiments as 'collapse'.

Figure 10 shows that when $\zeta / h_{\mathrm{f}}>1$ and $\mathrm{F}_{\mathrm{i}} / \mathrm{F}_{\mathrm{v}}>1$, foam collapse occurs. Even for $\zeta / h_{\mathrm{f}}<1$ foam collapse occurs, when $\mathrm{F}_{\mathrm{i}} / \mathrm{F}_{\mathrm{v}} \gg 1$. The black line of $\mathrm{F}_{\mathrm{i}} / \mathrm{F}_{\mathrm{v}}=\left(\zeta / h_{\mathrm{f}}\right)^{-9 / 4}$, divides the regimes of foam collapse well, whose slope may originate from the angular frequency dependence of $\zeta$ in Eq.(5). We thus conclude that foam collapse is controlled by these two non-dimensional numbers. Note that this scaling can explain the collapse of foams in both a single-foam layer and a foam layer overlying a liquid layer.

Despite that $\zeta / h_{\mathrm{f}}$ is a maximum estimate (Figure 9$), \zeta / h_{\mathrm{f}}$ explains the threshold well. Again, we infer that the foam is opaque and the deformation of its inside is larger than that observed from the wall as we discussed based on Figure 7.

Figure 10 also shows that the threshold of the foam collapse does not depend on the presence of the particles. We infer that the particles used in these experiments are sufficiently small not to make a density anomaly to enhance the foam 
collapse by oscillation. Because of the technical limitations of the shaking table, we could not conduct experiments in the regime of $\zeta / h_{\mathrm{f}}>1$ and $\mathrm{F}_{\mathrm{i}} / \mathrm{F}_{\mathrm{v}}<1$.

\section{Implications for triggering of eruptions}

In Section 5, we described the conditions for foam collapse by sloshing in a regime diagram using two non-dimensional numbers (Figure10). In this section, we apply our experimental results to natural magma reservoirs. We first consider the geometries of reservoir to resonate with seismic waves (Section 6.1). Next, we calculate possible strain of magma foams and strength of bubbles in magmas to constrain the conditions for magma foam collapse (Sections 6.2). We then summarize the phenomena possibly occurring in magma reservoirs (Section 6.3). Finally, we apply our scaling to Mt. Fuji 1707 eruption as a specific example (Section 6.4).

\subsection{Resonance frequencies of magma reservoirs}

While the details of the dynamics of sloshing are difficult to calculate theoretically due to many unknowns in natural volcanoes such as a conduit or reservoir geometry and density gradient within the magma reservoir, it is possible to assess, based on simple scaling considerations.

The natural frequencies of sloshing for a fluid layer depend on the ratio of the thickness and width of the layer $(h / l)$. The analytical estimates and experiments show that, for a rectangular and conduit-like upright circular cylindrical tank, the resonance frequency increases with the thickness of the fluid layer and approaches an asymptotical value (Faltinsen and Timokha, 2009). This is because the resonance frequency is determined by the ratio $(c / l)$ of the wave propagation velocity $(c)$ and the width of the tank $(l)$. For a thin fluid layer $(h \ll \lambda)$ the wave velocity increases with its thickness $(c=\sqrt{g h})$, as discussed with Eq.(3), but for a sufficiently thick layer $(h \gg \lambda)$ the wave velocity becomes independent from the fluid thickness $(c=\sqrt{g \lambda})$ as discussed with Eq.(4). For a constant width tank, the resonance frequency approaches an asymptotical value 
with increasing fluid thickness. This is the condition in our experiments using fixed dimensions.

In Figure 11, the fundamental mode of resonance frequencies of a rectangular magma reservoir is calculated by using Eq.(2) as a function of various liquid thickness and reservoir widths. The tinted region indicates the frequency ranges of seismic waves (e.g., Koketsu and Miyake, 2008; Psimoulis et al., 2014). The frequency of $1 \mathrm{~Hz}$ is commonly observed while lower frequencies are observed only for larger earthquakes or soft ground regions. An extraordinarily large earthquake ( $\geq$ M 9) may excite seismic waves with lower frequency components $(<0.05 \mathrm{~Hz})$.

Figure 11 shows that vertically elongated magma reservoirs are likely to resonate with seismic waves. A narrow volcanic conduit, $l<10 \mathrm{~m}$, can resonate with seismic waves irrespective of its vertical extension. The conduit diameter at active basaltic volcanoes is generally estimated as several meters (e.g., Kazahaya et al., 1994; Burton et al., 2007), and their height is greater than width. Magmas at shallow depth in such a conduit can resonate with seismic waves with frequencies of $0.3-1 \mathrm{~Hz}$. The fact that seismic waves with frequency components $<1 \mathrm{~Hz}$ can resonate with magma reservoirs is consistent with the observation that long-period waves are more effective at triggering than comparable amplitude short-period waves (Brodsky and Prejean, 2005).

Some magma reservoirs are shaped as horizontal sills. Typical horizontal sizes may be from a few hundreds of meters to tens of kilometers (e.g., Marsh, 2015). For a horizontally elongated magma reservoir, a width of $l \sim 200 \mathrm{~m}$ is a maximum scale to resonate with seismic waves. An approximately rectangular or large cylindrical magma reservoir whose horizontal size exceeds $l \geq 1 \mathrm{~km}$ is usually difficult to resonate. Therefore, resonance is to be more expected in conduit-like reservoirs rather than in extended chambers.

When the magma reservoir has a shape of vertical disk or a spherical chamber, the resonance frequency depends on the filling level (Mciver, 1989; Faltinsen and Timokha, 2009). This is because the length scale of free surface for wave propagation $(l)$ becomes shorter for a fully filled reservoir. Even a large chamber 
with a size of $l \sim 1 \mathrm{~km}$ at an intermediate depth may be able to resonate with seismic waves, if its filling level is high.

In a solidifying magma reservoir, phenocrysts exist in a silicate melt. If the magma is a crystal mush in which volume fraction of phenocrysts are close to the random closed packing fraction, the crystal mush behaves like a solid (e.g., Mader et al., 2013) and then sloshing is unlikely to occur. If a core with lower viscosity in the reservoir exists in a crystal mush, it will likely oscillate by sloshing (Bachmann and Bergantz, 2008). We consider that the inertial effect of phenocrysts is negligible, because the density contrast between the melt and phenocrysts is smaller than that between the bubbles and melt, which is observed in our experiments.

\subsection{Conditions leading to magma foam collapse}

Here, we estimate the possible sway amplitudes in a magma reservoir, and roughly estimate the conditions for foam collapse. In order to calculate $\zeta$ defined in Eq.(5), we have to estimate $\omega$ and $A$.

For angular frequency $\omega$, we use the resonance frequency $\omega=2 \pi f_{\mathrm{r}}$ defined in Eq.(2). If the magma reservoir has a vertically elongated conduit-like shape, the sway occurs only in the shallow region. In this case, the width of the conduit determines the wavelength of the sway, in turn the wave length regulates the depth of the flow, so that $l \sim \lambda / 2 \sim h$.

The horizontal tank displacement $(A)$ consists with the ground displacement during real earthquakes. Ground motions are frequently measured by velocity rather than displacement, and ground velocity is estimated by $v_{\mathrm{g}}=A \omega$. We thus calculate the sway amplitude $(\zeta)$ for arbitrary ground displacement amplitudes $(A)$, and plot it as a function of ground velocity $\left(v_{\mathrm{g}}\right)$.

In Figure 12, the largest sway amplitude is obtained for the blue thick line, suggesting that the sway amplitude becomes larger for less viscous magmas in a larger reservoir. During a strong earthquake, the observed velocity of the ground can exceed $1 \mathrm{~m} \mathrm{~s}^{-1}$ (Koketsu and Miyake, 2008). The viscosity of pre-eruptive basaltic melt is $1-10^{3} \mathrm{~Pa}$ s (Takeuchi, 2015). For a strong ground motion with 
a velocity of $1 \mathrm{~m} \mathrm{~s}^{-1}$, basaltic magma in a conduit several meters wide generates a sway amplitude of $1 \mathrm{~m}$. If a thin $(<1 \mathrm{~m})$ foam layer exists above a melt layer, the foam plausibly collapses. When the foam has large bubbles, a foam layer $\zeta / h_{\mathrm{f}}<1$ can collapse (Figure 10)

The foam strength is evaluated by Eq.(10) and depends on $A \omega$, which has a dimension of velocity. Again, we approximate the ground velocity $v_{\mathrm{g}} \sim A \omega$. Figure 13 shows calculated thresholds of foam strength $\mathrm{F}_{\mathrm{i}} / \mathrm{F}_{\mathrm{v}}=1$. When the liquid viscosity of the foam is sufficiently low $\left(\eta_{\mathrm{f}}<10 \mathrm{~Pa} \mathrm{~s}\right)$ and the bubble size is sufficiently large $(R>1 \mathrm{~mm})$, a seismic wave with large ground velocity $v_{\mathrm{g}}>0.1 \mathrm{~m} \mathrm{~s}^{-1}$ may destroy the foam. A bubble size of $R>1 \mathrm{~mm}$ has been observed in erupted scoriae (e.g., Mangan and Cashman, 1996; Lautze and Houghton, 2007). Foams with more viscous magma can collapse when the bubbles are larger and ground velocity of the seismic wave is faster. Note that low-frequency seismic waves (periods of 10 to $30 \mathrm{~s}$ ) possibly causing triggered activities are more likely Love- and Rayleigh- surface waves than body waves. The vertical component associated with Rayleigh waves may also contribute to induce fluid motion. Indeed, vertical shaking also causes surface undulation known as Faraday instability (e.g., Faraday, 1831; Bronfort and Caps, 2012).

\subsection{Possible scenarios in magma reservoir}

We present a conceptual model illustrating the conditions necessary for a magma reservoir to be affected by sloshing as well as the outcome the process may have (Figure 14).

Open conduits at volcanoes (e.g. lava lakes, summit conduits), which contain low-viscosity magma with a free surface, or alternatively magma reservoirs where a foam layer has accumulated below the roof, are possible candidates for sloshing-induced degassing. The filling fraction of the magma reservoir affects the sloshing dynamics significantly. If a vacant space is present above the foam layer, the surface of the foam undulates. Even when the magma reservoir is filled up, a layered structure where a foam layer overlies a dense melt layer may allow sloshing. On the other hand, when the magma reservoir is filled up 
by a uniform foam or a liquid layer, the fluid inside the tank does not move (Figure 4).

When sloshing occurs and the energy supplied by the seismic waves is sufficiently large, the bubbles in the foam deform to be interconnected, and then foam collapses. The conditions required for the foam collapse are summarized in Figure 10. Low viscosity both for the foam and dense layer favor foam collapse (Figure 12 and 13). A seismic wave with significant energy at the resonance frequency is efficient in originating large sway amplitudes.

After foam collapse, some part of volcanic gases separate from the surrounding melt and obtain mobility. At a top of an open conduit, a foam collapse increases the injection of volcanic gasses into the atmosphere. Similarly, if a closed reservoir connects to the surface of the earth by narrow cracks, in which the viscous foam cannot ascend, the released gasses from the foam can get through the crack to be fumaroles because of their low viscosity. The escape of gases to the outside of the reservoir decompresses the inside of the reservoir, stimulating further volatile exsolution. If there exist sufficient amount of bubbles in the melt, the exsolved volatiles diffuse into preexisting bubbles rather than nucleate new bubbles, so that the bubble sizes increase. Given that larger bubbles easily deform, bubble growth can cause further foam collapses.

This could result in unusual outgassing (Cigolini et al., 2007; Walter et al., 2009), which in turn enhances the heat flux (Harris and Ripepe, 2007; Donne et al., 2010). Indeed, the Overlook crater lava lake in Kilauea shows transient outgassing bursts and weak explosive eruptions after rockfalls (Orr et al., 2013; Carey et al., 2013) which likely excite sloshing (Dawson and Chouet, 2014).

Foam collapse may also supply large bubbles into a conduit to originate gaseous eruptions such as Strombolian eruption (e.g., Jaupart and Vergniolle, 1988). The ascending bubble inside a closed reservoir increases pressure and may also trigger an increase of seismicity (Linde et al., 1994; West et al., 2005).

When the shaking continues for long time after the collapse of a foam layer, the remnant of the foam including phenocrysts and small bubbles mixes with the lower layer. Once the lower layer is saturated with volatiles, the bubbles 
and phenocrysts transported into the lower layer provide new nucleation sites for additional exsolution of volatiles. The following vesiculation pressurizes the inside reservoir to cause additional volcanic activity, including eruptions. This mechanism takes time and can explain delayed triggered eruptions. Mixing between the injected hot basalt and overlying silicic magma has been frequently pointed out as a trigger of a big eruption (e.g., Pallister et al., 1992; Murphy et al., 2000). Usually, newly injected basalt is heavier than overlying silicic magma. The mechanism of mixing is not obvious. Our experiments show that a strong seismic wave can mix density stratified magmas and favor vesiculation.

The duration of the oscillation also affects the occurrence of foam collapse. In our experiments we impose oscillations for 10 seconds which is shorter than the typical duration of strong ground motion (e.g., Anderson, 2007). The oscillation duration of natural earthquakes is likely long enough to collapse magmatic foams. This is especially true for large earthquakes followed by aftershocks, which also may contribute to elongate the oscillation duration. Also, the mechanical and thermal softening of a volcano may lead to secondary earthquake and enhance the resonance.

As we have discussed above, it is likely that magma foams collapse by sloshing, and trigger eruptions. However, the causal link between a triggering earthquake and a putative triggered response is always ambiguous. Most proposed mechanisms for earthquake-volcano triggering, although physically rigorous, remain very speculative when applied to specific cases, due to the difficulty to link univocally the complex processes leading to an eruption to geophysical measurements. The magma reservoir sloshing we propose does not make exception. We next estimate the possible parameter sets to consider whether the occurrence of sloshing can be recognized by observations.

A seismic wave at $0.5 \mathrm{~Hz}$ can resonate with a $3 \mathrm{~m}$ wide conduit (Figure 11). If we assume the amplitude of the seismic wave displacement is $0.1 \mathrm{~m}$, the velocity of the ground motion is $0.3 \mathrm{~m} \mathrm{~s}^{-1}$, which is a reasonable assumption. Ground displacement amplitudes of about $0.1 \mathrm{~m}$ may originate from the shaking due to an M 6 earthquake in the epicentral region, an M 6.5 at $10 \mathrm{~km}$ distance or 
an $\mathrm{M} 7.5$ at $100 \mathrm{~km}$. If a basaltic magma with a viscosity of $1 \mathrm{~Pa}$ s fills the conduit, the seismic waves may cause a sway amplitude of $1 \mathrm{~m}$ (Figure 12). If there exists a basaltic foam layer whose thickness is $1 \mathrm{~m}$, a bubble radius of $100 \mu \mathrm{m}$, a bubble volume fraction is $>0.6$ and the surrounding melt viscosity is $1 \mathrm{~Pa} \mathrm{~s}$, the foam collapses (Figure 13). If the bubble radius is larger, thicker foam layers can collapse (Figures 10). These conditions can be easily achieved at active basaltic volcanoes, but cannot for inactive volcanoes.

In this case, the sloshing energy is calculated as $E_{\mathrm{p}} \sim \rho g \zeta^{2} l^{2} / \pi \sim 7 \times 10^{4} \mathrm{~J}$ by Eq.(13), where we assume the density of magma as $2500 \mathrm{~kg} \mathrm{~m}^{-3}$. Given that a M 0.0 earthquake releases an energy of about $60 \mathrm{KJ}$, we see that the resonance could be measurable if the source locates at shallow depth with a very good network. Of course, the waves would not be very impulsive and the focal mechanism (assuming that it could be calculated) would not be double couple but complex, due to the sloshing hitting back and forth.

When the Rayleigh waves of a triggering earthquake reach a volcano and cause resonance in a magma reservoir, this could be seen both by broad band seismometers and high-frequency strain meters. We predict that around the sloshing frequency, the amplitude of oscillation would increase over a few cycles in stations close to the upper volcano conduit, or around the volcanic edifice if the reservoir is deep, while they would just register the earthquake shaking at stations far away. Of course, the seismic waves originated by the magma sloshing on the chamber or conduit walls are quickly dissipated around it, so the stations need to be very close to register the resonance. How close could be estimated by converting the sloshing energy in one cycle into seismic energy and then into equivalent moment or magnitude.

In any case, to test the above flow chart with real volcanoes, we need to know the pre-eruptive conditions in the magma reservoir; i.e., melt viscosity and bubble sizes. Especially, the shape of the magma reservoir is a key parameter for sloshing but is not well constrained, usually. 


\subsection{An application to Mt. Fuji}

Now, we apply our model to the 1707 Mt. Fuji Hoei eruption, which occurred 49 days after the Hoei earthquake. Both eruption and earthquake are well studied. Because of this short time interval after the Hoei earthquake, a causal relation has been suggested, (e.g., Yokoyama, 1971; Nakamura, 1975).

The Hoei eruption began with a Plinian eruption of dacite magma and developed into a basaltic Plinian eruption, which was uncommonly explosive as a basaltic eruption (e.g., Miyaji et al., 2011). Because of this transition in magma composition, more than two magma sources and their mixing has been suggested (e.g., Fujii et al., 2002; Kaneko et al., 2010; Miyaji et al., 2011). During the transition, the $\mathrm{SiO}_{2}$ content changed gradually and the measured bubble fraction in the pumices and scoriae became low (Miyaji et al., 2011). Available seismic tomographies show two velocity anomalies below current Mt Fuji. One is a low $-V_{P}$, low- $V_{S}$ and low $-V_{P} / V_{S}$ anomaly at depths of $7-17 \mathrm{~km}$ in which deep low-frequency (DLF) earthquakes are observed, suggesting existence of fluids, such as $\mathrm{H}_{2} \mathrm{O}$ and $\mathrm{CO}_{2}$. Another locates beneath it, a low- $\mathrm{V}_{\mathrm{P}}$, low- $\mathrm{V}_{\mathrm{S}}$ and high- $\mathrm{V}_{\mathrm{P}} / \mathrm{V}_{\mathrm{S}}$ anomaly at depths of $15-25 \mathrm{~km}$ that may represent a zone of basaltic partial melt (Nakamichi et al., 2007). This deeper anomaly is also electrically conductive (Aizawa et al., 2004).

Based on these observations of the current state of Mt. Fuji, it has been suggested that two vertically separated magma reservoirs existed before the Hoei earthquake. The static stress changes associated with the Hoei earthquake is estimated in which the normal stresses are reduced at shallow $(<8 \mathrm{~km})$ depth and increased at $20 \mathrm{~km}$ depth (Chesley et al., 2012). As a result, basaltic magma located in the deeper magma reservoir began ascending. An injection of basaltic magma into the upper silicic magma reservoir caused magma mixing (Fujii et al., 2002; Miyaji et al., 2011). Magma mixing associated with the Hoei earthquake is also supported by the observation of plagioclase phenocrysts originated from dacite magma found in basaltic scoriae. Based on the reverse zoning of $\mathrm{MgO}$ profiles in the plagioclase phenocrysts, the time duration after the magma mixing until eruption is estimated to be less than 49 days (Aruga 
et al., 2015).

However, a simple mixing cannot explain the observed low bubble fraction during the compositional transition from dacite to basaltic magmas (Miyaji et al., 2011). The silicic melt inclusions hosted by olivine phenocrysts in the scoriae suggest that basaltic magma coexisted with silicic magma (Kaneko et al., 2010). In addition, the depth of the magma chamber before the Hoei eruption is not necessarily the same as the current ones.

We thus conjecture that sloshing might have taken place, according to the following scenario (Figure 15a). 1) Dacite magma was cooling in a magma reservoir. Phenocrysts were growing so that the exsolved volatiles were forming bubbles. Long waiting times allowed bubbles to grow large in size with a high gas volume fraction. 2) Hot basaltic magma was gradually injected beneath the bubbly dacite magma foam, creating a density stratified structure. The melt viscosity of the dacite foam close to the interface was reduced by the heating from the underlying basaltic magma. 3) The Hoei earthquake shook the magma reservoir. The sway of the interface between the basalt and dacite layer deformed the bubbles in the dacite foam layer, inducing foam collapse. Part of the collapsed foam including the plagioclase phenocrysts and dissolved volatiles mixed with the lower basaltic layer. The basaltic layer was invaded by nucleation sites and the volatiles vesiculated. 4) The gas released from the collapsed foam ascended through the dacite layer, pressurizing the magma reservoir (Steinberg et al., 1989; Sahagian and Proussevitch, 1992; Pyle and Pyle, 1995). The newly nucleated bubbles in the basalt layer increased the volume of the magma in the reservoir. Lowered normal stress might have prompted the additional input of basaltic magma. These effects and/or a strong aftershock eventually triggered the eruption. 5) The magmas erupted out from the top of the reservoir. First, un-deformed dacite foam erupted out with high volume fraction of bubbles, next the collapsed dacite layer with a low bubble fraction, and then an andesite magma which may be a mixed basalt and dacite followed. Finally, an explosive eruption of basalt magma with high bubble fraction occurred. This scenario is consistent with observations (Fujii et al., 2002; Kaneko et al., 2010; Miyaji 
et al., 2011).

In Figure 15b, we estimate the possible parameters involved in this process. The estimated magnitude of the Hoei earthquake has a wide range from M 8.4 to close to M 9, but a recent estimate of tsunami heights suggests approximately a M 9.0 earthquake (e.g., Furumura et al., 2011; Ishibashi, 2004; Hyodo et al., 2014). Assuming M 9.0, the size of the source region had an extent of $\sim 400 \mathrm{~km}$ length and $\sim 150 \mathrm{~km}$ width and a slip displacement of $20 \mathrm{~m}$ (Hyodo and Hori, 2013). The Mt. Fuji locates at $350 \mathrm{~km}$ from the epicenter. Thus, the displacement amplitude of the seismic wave at Mt. Fuji is estimated as the order of $1 \mathrm{~m}$. Assuming that the rupture of the fault travels $150 \mathrm{~km}$ at $\mathrm{S}$ wave velocity of $5 \mathrm{~km} \mathrm{~s}^{-1}$, the frequency of the waves could have been as low as $0.03 \mathrm{~Hz}$ which can resonate a large magma reservoir of $1 \mathrm{~km}$ size (Figure 11). The erupted volume of the Hoei eruption is estimated as $1.6 \mathrm{~km}^{3}$ (Miyaji et al., 2011). We assume that the newly injected basalt was water rich and at high temperature $\left(>120{ }^{\circ} \mathrm{C}\right)$ so that the melt viscosity was $1 \mathrm{~Pa}$ s. The lines in Figure $15 \mathrm{~b}$ show the combination of bubble radius and foam thickness to be $\mathrm{F}_{\mathrm{i}} / \mathrm{F}_{\mathrm{v}}=\left(\zeta / h_{\mathrm{f}}\right)^{(-9 / 4)}$, the threshold of foam collapse shown by the black line in Figure 10. The difference of the line color indicates the dacite viscosity. The typical pre-eruptive dacite viscosity is $10^{3}-10^{4} \mathrm{~Pa}$ s. Here, the silicate melt viscosity is sensitive to temperature rather than $\mathrm{SiO}_{2}$ content (Takeuchi, 2015). As discussed above, the underlying hot basaltic magma heated up the overlying dacite magma, lowering its viscosity to values of $10^{2}-10^{3} \mathrm{~Pa}$ s. If the bubble radius in the foam layer is as large as $1 \mathrm{~mm}$, which is a reasonable assumption, $10 \mathrm{~m}$ thick dacite foam layer could have collapsed.

Thus, sloshing-induced foam collapse and magma mixing can explain the characteristics of the Mt. Fuji Hoei eruption with a reasonable combination of parameters. 


\section{Conclusions}

We conducted shaking experiments of viscous liquid and foams to simulate the sloshing in a magma reservoir induced by earthquakes. Our experimental results show that when there is a vacant space or density heterogeneities in the experimental tank, external oscillation induces sway of the fluid. Resonance may occur depending on the fluid layer shape, with the sway amplitude becoming large around the resonance frequencies. When the fluid inside the tank includes bubbles, the sway of the fluid may deform the bubbles until the bubble films rupture and the foam collapses. The collapsed foam may mix with the underlying liquid layer.

Based on our experimental results, we conclude that the parameters critical for the plausibility of this process are: the geometry of the magma reservoir or conduit, the density structure of the magma within the reservoir or conduit, the gas bubble size and fraction in the foams, and the melt viscosity. Seismic waves of frequency $>1 \mathrm{~Hz}$ are unlikely to induce resonance, because they would require conduits of width $<0.5 \mathrm{~m}$, which are thermally short-lived. Seismic waves with $\sim 1 \mathrm{~Hz}$ can collapse less viscous $\left(<10^{3} \mathrm{~Pa} \mathrm{~s}\right)$ basaltic magma foams with large bubbles $(1 \mathrm{~mm})$ in a conduit with several meters width. In order to oscillate magmas in a larger reservoir, seismic waves with lower frequency typical of large earthquakes are required. Once a larger reservoir without less internal obstructing walls resonates, the moving mass of fluid may become large, resulting in a more severe sloshing.

The volcanic gas released from the collapsed foam can increase the outgassing and heat flux, or may generate a large slug to cause Strombolian eruption. Further oscillation mixes the collapsed foam with the underlying melt layer to prepare a following eruption. These experimental results are applied to natural systems and help to explain the mechanism of triggered eruptions in a near field as well as far field. Results are consistent with the fact that only very few eruptions are triggered and that only some volcanoes respond to large earthquakes. The Hoei eruption of Mt. Fuji might be an example of a triggered 
eruption by sloshing, and serve as a well-studied case example that is applicable elsewhere as well.

Acknowledgments We thank Ralf Bauz, Stefan Mikulla, and Peter Neuendorf for their help in the GFZ bubble-lab, and Matthias Rosenau for providing the glucose syrup. Helpful and careful reviews by David P. Hill and an anonymous reviewer, and the journal editor, Lionel Wilson, and Maggie Mangan are deeply appreciated. This work was supported by KAKENHI 24681035, the European Union through the ERC StG project CCMP-POMPEI, grant number 230583, the European Supersite project MED-SUV, grant number 308665.

\section{Appendix. A: Sway amplitude}

The elevation of the liquid surface $\zeta$ should be determined by the energy balance (Keulegan, 1959; Faltinsen and Timokha, 2009; Sauret et al., 2015). During the sloshing, viscous dissipation reduces the sway amplitude. This effect is defined theoretically and measured by the decrease of sway amplitude after an impulse excitation

$$
\langle\dot{E}\rangle \sim \alpha \omega E_{\mathrm{p}} / \pi
$$

where $\langle\dot{E}\rangle$ is the energy dissipation over one cycle, and $\alpha$ indicates the damping by viscous dissipation (Keulegan, 1959; Faltinsen and Timokha, 2009).

$$
\alpha \propto \sqrt{\frac{\eta}{\rho \omega}} \frac{1}{l} .
$$

The potential flow energy within one wave length in a cycle of two-dimensional flow is

$$
E_{\mathrm{p}} \sim \rho g \zeta^{2} / k
$$

In our experiments, the fluid-filled tank is oscillated repeatedly. Some part 
822

of the energy input dissipates to determine the sway amplitude.

$$
E_{\mathrm{t}} \propto\langle\dot{E}\rangle / \omega \propto \alpha E_{\mathrm{p}}
$$

823 824 is

where the energy input by the tank oscillation in a cycle of two-dimensional flow is

$$
E_{\mathrm{t}} \sim \rho A^{2} \omega^{2} h l
$$

Assuming the thick fluid layer, $\sqrt{k} \sim \omega / \sqrt{g}$, and we obtain

$$
\zeta \propto \frac{A \omega^{2} \sqrt{h} l}{g\left(\sqrt{\frac{\eta}{\rho \omega}}\right)^{1 / 2}} .
$$

In Eq.(5), we determined the prefactor $1 /(2 \pi)$ by the fitting the experimental data.

\section{References}

Aizawa, K., Yoshimura, R., Oshiman, N., 2004. Splitting of the Philippine Sea Plate and a magma chamber beneath Mt. Fuji. Geophys. Res. Lett. 31, L09603, doi:10.1029/2004GL019477.

Anderson, J.G., 2007. Physical processes that control strong ground motion. Treatise Geophys. 4, 513-565.

Aruga, T., Nakamura, M., Okumura, S., Yoshimoto, M., 2015. A petrological test of the earthquake-trigger model of the Mt. Fuji Hoei eruption. JpGU Meeting, Makuhari, Chiba, Japan.

Bachmann, O., Bergantz, G., 2008. The Magma reservoirs that feed supereruptions. Elements 4, 17-21.

Bagdassarov, N., Dorfman, A., Dingwell, D.B., 2000. Effect of alkalis, phosphorus, and water on the surface tension of haplogranite melt. Am. Mineral. 85, $33-40$. 
Battaglia, J., Métaxian, J., Garaebiti, E., 2012. Earthquake-volcano interaction imaged by coda wave interferometry. Geophys. Res. Lett. 39, L11309, doi:10.1029/2012GL052003.

Bebbington, M.S., Marzocchi, W., 2011. Stochastic models for earthquake triggering of volcanic eruptions. J. Geophys. Res. 116, B05204, doi:10.1029/2010JB008114.

Bonali, F.L., 2013. Earthquake-induced static stress change on magma pathway in promoting the 2012 Copahue eruption. Tectonophys. 608, 127-137.

Bonali, F.L., Tibaldi, A., Corazzato, C., Tormey, D.R., Lara, L.E., 2013. Quantifying the effect of large earthquakes in promoting eruptions due to stress changes on magma pathway: The Chile case. Tectonophys. 583, 54-67.

Brenguier, F., Campillo, M., Takeda, T., Aoki, Y., Shapiro, N.M., Briand, X., Emoto, K., Miyake, H., 2014. Mapping pressurized volcanic fluids from induced crustal seismic velocity drops. Science 345, 80-82.

Brodsky, E.E., Prejean, S.G., 2005. New constraints on mechanisms of remotely triggered seismicity at Long Valley Caldera. J. Geophys. Res. 110, B04302, doi:10.1029/2004JB003211.

Bronfort, A., Caps, H., 2012. Faraday instability at foam-water interface. Phys. Rev. E 86, 066313.

Burton, M.R., Mader, H.M., Polacci, M., 2007. The role of gas percolation in quiescent degassing of persistently active basaltic volcanoes. Earth Planet. Sci. Lett. 264, 46-60.

Candela, T., Brodsky, E.E., Marone, C., Elsworth, D., 2014. Laboratory evidence for particle mobilization as a mechanism for permeability enhancement via dynamic stressing. Earth Planet. Sci. Lett. 392, 279-291.

Cannata, A., Grazia, G.D., Montalto, P., Aliotta, M., Patane, D., Boschi, E., 2010. Response of mount Etna to dynamic stresses from distant earthquakes. J. Geophys. Res. 115, B12304, doi:10.1029/2010JB007487. 
Carey, R.J., Manga, M., Degruyter, W., Gonnermann, H., Swanson, D., Houghton, B., Orr, T., Patrick, M., 2013. Convection in a volcanic conduit recorded by bubbles. Geology 41, 395-398.

Chesley, C., LaFemina, P.C., Puskas, C., Kobayashi, D., 2012. The 1707 Mw8.7 Hoei earthquake triggered the largest historical eruption of Mt. Fuji. Geophys. Res. Lett. 39, L24309, doi:10.1029/2012GL053868.

Cigolini, C., Laiolo, M., Coppola, D., 2007. Earthquake - volcano interactions detected from radon degassing at Stromboli (Italy). Earth Planet. Sci. Lett. $257,511-525$

Crews, J.B., Cooper, C.A., 2014. Experimental evidence for seismically initiated gas bubble nucleation and growth in groundwater as a mechanism for coseismic borehole water level rise and remotely triggered seismicity. J. Geophys. Res. 119, 7079.7091, doi:10.1002/2014JB011398.

Dawson, P., Chouet, B., 2014. Characterization of very-long-period seismicity accompanying summit activity at Kilauea Volcano, Hawai'i: 2007-2013. J. Volcanol. Geotherm. Res. 278-279, 59-85.

Donne, D.D., Harris, A.J.L., Ripepe, M., Wright, R., 2010. Earthquake-induced thermal anomalies at active volcanoes. Geology 38, 771-774.

Eggert, S., Walter, T.R., 2009. Volcanic activity before and after large tectonic earthquakes: Observations and statistical significance. Tectonophys. 471, 1426.

Elkhoury, J.E., Brodsky, E.E., Agnew, D.C., 2006. Seismic waves increase permeability. Nature 441, 1135-1138.

Faltinsen, O.M., Timokha, A.N., 2009. Sloshing. Cambridge University Press, Cambridge, pp.606.

Faraday, M., 1831. On a peculiar class of acoustical figures; and on certain forms assumed by groups of particles upon vibrating elastic surfaces. Philos. Trans. R. Soc. London 121, 299-340. 
Fujii, T., Yoshimoto, M., Yasuda, A., 2002. A perspective on next Mt. Fuji Eruption (in Japanese). Monthly Earth 24, 617-621.

Fujita, E., Kozono, T., Ueda, H., Kohno, Y., Yoshioka, S., Toda, N., Kikuchi, A., Ida, Y., 2013. Stress field change around the Mount Fuji volcano magma system caused by the Tohoku megathrust earthquake, Japan. Bull. Volcanol. 75,679 .

Furumura, T., Imai, K., Maeda, T., 2011. A revised tsunami source model for the 1707 Hoei earthquake and simulation of tsunami inundation of Ryujin Lake, Kyushu, Japan. J. Geophys. Res. 116, B02308, doi:10.1029/2010JB007918.

Harris, A.J.L., Ripepe, M., 2007. Regional earthquake as a trigger for enhanced volcanic activity: Evidence from MODIS thermal data. Geophys. Res. Lett. 34, L02304, doi:10.1029/2006GL028251.

Hatayama, K., 2008. Lessons from the 2003 Tokachi-oki, Japan, earthquake for prediction of long-period strong ground motions and sloshing damage to oil storage tanks. J. Seismol. 12, 255-263.

Hill, D.P., Pollitz, F., Newhall, C., 2002. Earthquake - volcano interactions. Phys. Today 55, 41-47.

Hill, D.P., Prejean, S.G., 2007. Dynamic triggering. Treatise Geophys. 4, 257291.

Hill, D.P., Reasenberg, P.A., Michael, A., Arabaz, W.J., Beroza, G., Brumbaugh, D., Brune, J.N., Castro, R., Davis, S., dePolo, D., Ellsworth, W.L., Gomberg, J., Harmsen, S., House, L., Jackson, S.M., Johnston, M.J.S., Jones, L., Keller, R., Malone, S., Munguia, L., Nava, S., Pechmann, J.C., Sanford, A., Simpson, R.W., Smith, R.B., Stark, M., Stickney, M., Vidal, A., Walter, S., Wong, V., Zollweg, J., 1993. Seismicity remotely triggered by the magnitude 7.3 Landers, California, Earthquake. Science 260, 1617-1623. 
Housner, G.W., 1957. Dynamic pressures on accelerated fluid containers. Bull. Seismol. Soc. Am. 47, 15-35.

Housner, G.W., 1963. The dynamic behavior of water tanks. Bull. Seismol. Soc. Am. 53, 381-387.

Hurwitz, S., Sohn, R.A., Luttrell, K., Manga, M., 2014. Triggering and modulation of geyser eruptions in Yellowstone National Park by earthquakes, earth tides, and weather. J. Geophys. Res. 119, 1718-1737, doi:10.1002/2013JB010803.

Hyodo, M., Hori, T., 2013. Re-examination of possible great interplate earthquake scenarios in the Nankai Trough, southwest Japan, based on recent findings and numerical simulations. Tectonophys. 600, 175-186.

Hyodo, M., Hori, T., Ando, K., Baba, T., 2014. The possibility of deeper or shallower extent of the source area of Nankai Trough earthquakes based on the 1707 Hoei tsunami heights along the Pacific and Seto Inland Sea coasts, southwest Japan. Earth, Planets Space 66, 123.

Ishibashi, H., 2009. Non-Newtonian behavior of plagioclase-bearing basaltic magma: Subliquidus viscosity measurement of the 1707 basalt of Fuji volcano, Japan. J. Volcanol. Getotherm. Res. 181, 78-88.

Ishibashi, K., 2004. Status of historical seismology in Japan. Ann. Geophys. 47, $339-368$.

Jaupart, C., Vergniolle, S., 1988. Laboratory models of Hawaiian and Strombolian eruptions. Nature 331, 58-60.

Kaneko, T., A. Yasuda, T.F., Yoshimoto, M., 2010. Crypto-magma chambers beneath Mt. Fuji. J. Volcanol. Geotherm. Res. 193, 161-170.

Kazahaya, K., Shinohara, H., Saito, G., 1994. Excessive degassing of izu-oshima volcano: magma convection in a conduit. Bull. Volcanol. 56, 207-2016. 
Keulegan, G.H., 1959. Energy dissipation in standing waves in rectangular basins. J. Fluid Mech. 6, 33-50.

Koketsu, K., Miyake, H., 2008. A seismological overview of long-period ground motion. J. Seismol. 12, 133-143.

Landau, L.D., Lifshitz, E.M., 1987. Fluid Mechanics, Second Edition: Volume 6 (Course of Theoretical Physics). Butterworth-Heinemann, Oxford, pp.539.

Lautze, N.C., Houghton, B.F., 2007. Linking variable explosion style and magma textures during 2002 at Stromboli volcano, Italy. Bull. Volcanol. 69, 445-460.

Lev, E., Spiegelman, M., Wysocki, R.J., Karson, J.A., 2012. Investigating lava flow rheology using video analysis and numerical flow models. J. Volcanol. Geotherm. Res. 247-248, 62-73.

Linde, A.T., Sacks, I.S., 1998. Triggering of volcanic eruptions. Nature 395, 888-890.

Linde, A.T., Sacks, I.S., Johnston, M.J.S., Hill, D.P., Bilham, R.G., 1994. Increased pressure from rising bubbles as a mechanism for remotely triggered seismicity. Nature 371, 408-410.

Mader, H.M., Llewellin, E.W., Mueller, S.P., 2013. The rheology of two-phase magmas: A review and analysis. J. Volcanol. Geotherm. Res. 527, 135-158.

Manga, M., Beresnev, I., Brodsky, E.E., Elkhoury, J.E., Elsworth, D., Ingebritsen, S.E., Mays, D.C., Wang, C.Y., 2012. Changes in permeability caused by transient stresses: Field observations, experiments, and mechanisms. Rev. Geophys. 50, RG2004, doi:10.1029/2011RG000382.

Manga, M., Brodsky, E., 2006. Seismic triggering of eruptions in the far field: Volcanoes and geysers. Annu. Rev. Earth Planet. Sci. 34, 263-91.

Mangan, M., Sisson, T., 2005. Evolution of melt-vapor surface tension in silicic volcanic systems: Experiments with hydrous melts. J. Geophys. Res. 110, B01202, doi:10.1029/2004JB003215. 
Mangan, M.T., Cashman, K.V., 1996. The structure of basaltic scoria and reticulite and inferences for vesiculation, foam formation, and fragmentation in lava fountains. J. Volcanol. Geotherm. Res. 73, 1-18.

Marsh, B.D., 2015. Magma chambers, in: Sigurdsson, H. (Ed.), The Encyclopedia of Volcanoes, 2nd Edition. Academic Press, Amsterdam, 113-141.

Marzocchi, W., 2002. Remote seismic influence on large explosive eruptions. J. Geophys. Res. 107, doi:B12018, 10.1029/2001JB000307.

Marzocchi, W., Casarotti, E., Piersanti, A., 2002. Modeling the stress variations induced by great earthquakes on the largest volcanic eruptions of the 20th century. J. Geophys. Res. 107, 2320, doi:10.1029/2001JB001391.

Mciver, P., 1989. Sloshing frequencies for cylindrical and spherical containers filled to an arbitrary depth. J. Fluid Mech. 201, 243-257.

Miyaji, N., Kan'no, A., Kanamaru, T., Mannen, K., 2011. High-resolution reconstruction of the Hoei eruption (AD 1707) of Fuji volcano, Japan. J. Vocanol. Geotherm. Res. 207, 113-129.

Murphy, M.D., Sparks, R.S.J., Barclay, J., Carroll, M.R., Brewer, T.S., 2000. Remobilization of andesite magma by intrusion of mafic magma at the Soufriere Hills volcano, Montserrat, West Indies. J. Petrol. 41, 21-42.

Nakamichi, H., Watanabe, H., Ohminato, T., 2007. Three-dimensional velocity structures of Mount Fuji and the South Fossa Magna, central Japan. J. Geophys. Res. 112, B03310, doi:10.1029/2005JB004161.

Nakamura, K., 1975. Volcano structure and possible mechanical correlation between volcanic eruptions and earthquakes. Bull. Volcanol. Soc. Japan 2, 229-240.

Namiki, A., 2012. An empirical scaling of shear-induced outgassing during magma ascent: Intermittent magma ascent causes effective outgassing. Earth Planet. Sci. Lett. 353-354, 72-81. 
Nostro, C., Stein, R.S., Cocco, M., Belardinelli, M.E., Marzocchi, W., 1998. Two-way coupling between Vesuvius eruptions and southern Apennine earthquakes, Italy, by elastic stress transfer. J. Geophys. Res. 103, 24487-24504.

Ohta, T., Zama, S., 2005. Large earthquakes and large-scale structures (in Japanese). Kyoritsu Shuppan, Tokyo, pp.287.

Okumura, S., Nakamura, M., Uesugi, K., Nakano, T., Fujioka, T., 2013. Coupled effect of magma degassing and rheology on silicic volcanism. Earth Planet. Sci. Lett. 362, 163-170.

Orr, T.R., Thelen, W.A., Patrick, M.R., Swanson, D.A., Wilson, D.C., 2013. Explosive eruptions triggered by rockfalls at Kilauea volcano, Hawaiei. Geology 41, 207-210.

Pallister, J.S., Hoblitt, R.P., Reyes, A., 1992. A basalt trigger for the 1991 eruptions of Pinatubo volcano? Nature 356, 426-428.

Popov, G., Sankar, S., Sankar, T.S., Vatistas, G.H., 1992. Liquid sloshing in rectangular road containers. Comput. Fluid 21, 551-569.

Psimoulis, P.A., Houlie, N., Michel, C., Meindl, M., Rothacher, M., 2014. Longperiod surface motion of the multipatch Mw9.0 Tohoku-Oki earthquake. Geophys. J. Int. 199, 968-980.

Pyle, D.M., Pyle, D.L., 1995. Bubble migration and the initiation of volcanic eruptions. J. Volvanol. Geotherm. Res. 67, 227-232.

Rebouillat, S., Liksonov, D., 2010. Fluid-structure interaction in partially filled liquid containers: A comparative review of numerical approaches. Comput. Fluids 39, 739-746.

Romero, J.A., Ramirez, O., Fortanell, J.M., Martinez, M., Lozano, A., 2006. Analysis of lateral sloshing forces within road containers with high fill levels. Proc. IMechE. Part D: J. Automob. Eng. 220, 303-312. 
Sahagian, D.L., Proussevitch, A.A., 1992. Bubble in volcanic systems. Nature 359,485 .

Sauret, A., Boulogne, F., Cappello, J., Dressaire, E., Stone, H.A., 2015. Damping of liquid sloshing by foams. Phys. Fluids 27, 022103.

Sparks, S.R.J., Sigurdsson, H., Wilson, L., 1977. Magma mixing: a mechanism for triggering acid explosive eruptions. Nature 267, 315-318.

Steinberg, A., Steinberg, A.S., Merzhanov, A.G., 1989. Fluid mechanism of pressure growth in volcanic (magmatic) systems. Mod. Geol. 13, 257-265.

Sumita, I., Manga, M., 2008. Suspension rheology under oscillatory shear and its geophysical implications. Earth Planet. Sci. Lett. 269, 467-477.

Sutton, M.A., Orteu, J.J., Schreier, H., 2009. Image Correlation for Shape, Motion and Deformation Measurements: Basic Concepts,Theory and Applications. Springer, New York., pp.342.

Takada, Y., Fukushima, Y., 2013. Volcanic subsidence triggered by the 2011 Tohoku earthquake in Japan. Nature Geosci. 6, 637-641.

Takeuchi, S., 2015. A melt viscosity scale for preeruptive magmas. Bull. Volcanol. 77,41 .

Thiagarajan, K.P., Rakshit, D., Repalle, N., 2011. The air-water sloshing problem: Fundamental analysis and parametric studies on excitation and fill levels. Ocean Eng. 38, 498-508.

Viccaro, M., Ferlito, C., Cortesogno, L., Cristofolini, R., Gaggero, L., 2006. Magma mixing during the 2001 event at Mount Etna (Italy): Effects on the eruptive dynamics. J. Volcanol. Geotherm. Res. 149, 139-159.

Vona, A., Romano, C., Dingwell, D.B., Giordano, D., 2011. The rheology of crystal-bearing basaltic magmas from Stromboli and Etna. Geochem. Cosmochem. Acta 75, 3214-3236. 
Walter, T.R., 2007. How a tectonic earthquake may wake up volcanoes: Stress transfer during the 1996 earthquake-eruption sequence at the Karymsky Volcanic Group, Kamchatka. Earth Planet. Sci. Lett. 264, 347-359.

Walter, T.R., 2011. Structural architecture of the 1980 Mount St. Helens collapse: An analysis of the Rosenquist photo sequence using digital image correlation. Geology 39, 767-770.

Walter, T.R., Amelung, F., 2006. Volcano-earthquake interaction at Mauna Loa volcano, Hawaii,. J. Geophys. Res. 111, B05204, doi:10.1029/2005JB003861.

Walter, T.R., Amelung, F., 2007. Volcanic eruptions following $M \geq 9$ megathrust earthquakes: Implications for the Sumatra-Andaman volcanoes. Geology 35, $539-542$.

Walter, T.R., Wang, R., Acocella, V., Neri, M., Grosser, H., Zschau, J., 2009. Simultaneous magma and gas eruptions at three volcanoes in southern Italy: An earthquake trigger? Geology 37, 251-254.

Watt, S.F.L., Pyle, D.M., Mather, T.A., 2009. The influence of great earthquakes on volcanic eruption rate along the Chilean subduction zone. Earth Planet. Sci. Lett. 277, 399-407.

West, M., Sánchez, J.J., McNutt, S.R., 2005. Periodically triggered seismicity at Mount Wrangell, Alaska, after the Sumatra Earthquake. Science 308, $1144-1146$.

Winkler, C., 2000. Rollover of heavy commercial vehicles. UMTRI Res. Rev. $31,1-20$

Woith, H., Wang, R., Milkereit, C., Zschau, J., Maiwald, U., Pekdeger, A., 2003. Heterogeneous response of hydrogeological systems to the Izmit and Duzce (Turkey) earthquakes of 1999. Hydrogeol. J. 11, 113-121.

Yokoyama, I., 1971. Volcanic eruptions triggered by tectonic earthquakes. Geophysical bulletin of the Hokkaido University 25, 129-139. 
${ }_{1084}$ Yukutake, Y., Honda, R., Harada, M., Aketagawa, T., Ito, H., Yoshida, A., 2011. Remotely-triggered seismicity in the Hakone volcano following the 2011 off the Pacific coast of Tohoku Earthquake. Earth Planet Space 63, 737-740.

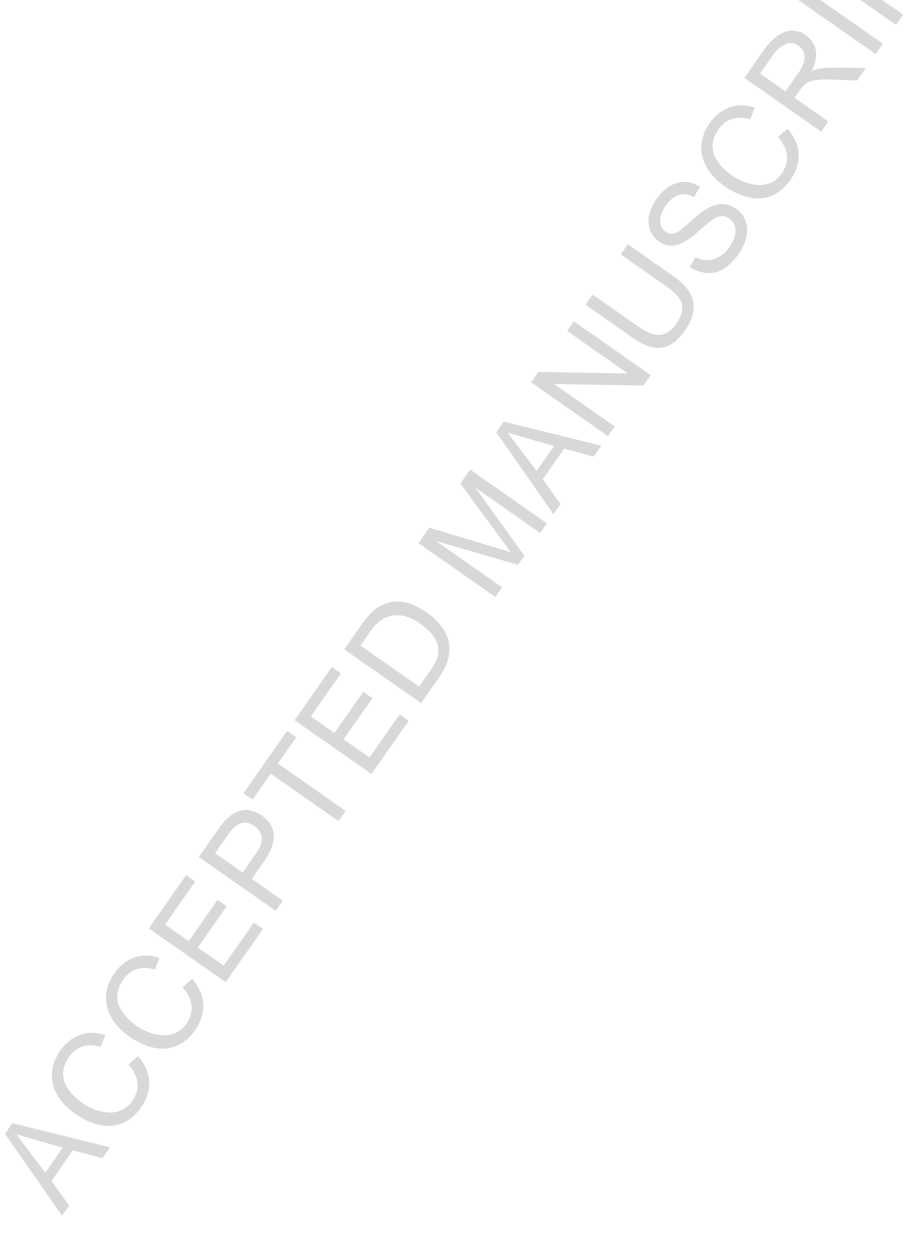


Table 1: Notations.

\begin{tabular}{|c|c|c|}
\hline Parameter & Unit & Description \\
\hline$A$ & $\mathrm{~m}$ & Amplitude of the horizontal displacement of the tank \\
\hline$c$ & $\mathrm{~m} \mathrm{~s}^{-1}$ & Wave propagation velocity \\
\hline$f$ & $\mathrm{~Hz}$ & Frequency \\
\hline$f_{\mathrm{r}}$ & $\mathrm{Hz}$ & Resonance frequency defined in Eq.(2) \\
\hline $\mathrm{F}_{\mathrm{i}}$ & $\mathrm{N}$ & Inertia force acting on a bubble defined in Eq.( 7$)$ \\
\hline $\mathrm{F}_{\mathrm{v}}$ & $\mathrm{N}$ & Viscous force acting on a bubble membrane defined in Eq.(8) \\
\hline$g$ & $\mathrm{~m} \mathrm{~s}^{-2}$ & Gravitational acceleration \\
\hline$h$ & $\mathrm{~m}$ & Thickness of the liquid layer \\
\hline$h_{\mathrm{f}}$ & $\mathrm{m}$ & Thickness of the foam layer \\
\hline$k$ & $\operatorname{rad~} \mathrm{m}^{-1}$ & Wave number \\
\hline$l$ & $\mathrm{~m}$ & Width of the tank \\
\hline$M$ & $\mathrm{~kg}$ & Mass of the shaking fluid \\
\hline$n$ & & Positive integer \\
\hline$R$ & & Bubble radius \\
\hline$t$ & & Time \\
\hline$v_{\mathrm{g}}$ & $1 \mathrm{~s}$ & Ground velocity \\
\hline$\delta$ & $\mathrm{m}$ & Thickness of bubble membrane defined in Eq.(9) \\
\hline$\eta$ & $\mathrm{Pa} \mathrm{s}$ & Viscosity \\
\hline$\eta_{\mathrm{f}}$ & Pa s & Liquid viscosity of foam \\
\hline$\lambda$ & $\mathrm{m}$ & Wavelength \\
\hline$\omega$ & $\operatorname{rad~s}^{-1}$ & Angular frequency \\
\hline$\phi_{\mathrm{b}}$ & - & Volume fraction of bubble \\
\hline$\phi_{\mathrm{p}}$ & - & Volume fraction of particles \\
\hline$\rho$ & $\mathrm{kg} \mathrm{m}^{-3}$ & Density of liquid \\
\hline$\rho^{*}$ & $\mathrm{~kg} \mathrm{~m}{ }^{-3}$ & Effective density determining $\zeta$ used in Eq.(5) \\
\hline$\zeta$ & $\mathrm{m}$ & Amplitude of free surface wave (sway amplitude) \\
\hline$\zeta / h_{\mathrm{f}}$ & - & Strain of the foam layer \\
\hline
\end{tabular}




$\begin{array}{rccc}\text { Frequency } & \text { Amplitude } & \text { accerelation a/g } \\ 0.1 & 1.00 \mathrm{E}-03 & 3.94 \mathrm{E}-04 & 4.02 \mathrm{E}-05 \\ 0.3 & 1.00 \mathrm{E}-03 & 3.55 \mathrm{E}-03 & 3.62 \mathrm{E}-04 \\ 1 & 1.00 \mathrm{E}-03 & 3.94 \mathrm{E}-02 & 4.02 \mathrm{E}-03 \\ 3 & 1.00 \mathrm{E}-03 & 3.55 \mathrm{E}-01 & 3.62 \mathrm{E}-02 \\ 10 & 1.00 \mathrm{E}-03 & 3.94 \mathrm{E}+00 & 4.02 \mathrm{E}-01 \\ 0.1 & 3.00 \mathrm{E}-03 & 1.18 \mathrm{E}-03 & 1.21 \mathrm{E}-04 \\ 0.3 & 3.00 \mathrm{E}-03 & 1.06 \mathrm{E}-02 & 1.09 \mathrm{E}-03 \\ 1 & 3.00 \mathrm{E}-03 & 1.18 \mathrm{E}-01 & 1.21 \mathrm{E}-02 \\ 3 & 3.00 \mathrm{E}-03 & 1.06 \mathrm{E}+00 & 1.09 \mathrm{E}-01 \\ 10 & 3.00 \mathrm{E}-03 & 1.18 \mathrm{E}+01 & 1.21 \mathrm{E}+00 \\ 0.1 & 1.00 \mathrm{E}-02 & 3.94 \mathrm{E}-03 & 4.02 \mathrm{E}-04 \\ 0.3 & 1.00 \mathrm{E}-02 & 3.55 \mathrm{E}-02 & 3.62 \mathrm{E}-03 \\ 1 & 1.00 \mathrm{E}-02 & 3.94 \mathrm{E}-01 & 4.02 \mathrm{E}-02 \\ 3 & 1.00 \mathrm{E}-02 & 3.55 \mathrm{E}+00 & 3.62 \mathrm{E}-01 \\ 10 & 1.00 \mathrm{E}-02 & 3.94 \mathrm{E}+01 & 4.02 \mathrm{E}+00 \\ 0.1 & 3.00 \mathrm{E}-02 & 1.18 \mathrm{E}-02 & 1.21 \mathrm{E}-03 \\ 0.3 & 3.00 \mathrm{E}-02 & 1.06 \mathrm{E}-01 & 1.09 \mathrm{E}-02 \\ 1 & 3.00 \mathrm{E}-02 & 1.18 \mathrm{E}+00 & 1.21 \mathrm{E}-01 \\ 3 & 3.00 \mathrm{E}-02 & 1.06 \mathrm{E}+01 & 1.09 \mathrm{E}+00 \\ 10 & 3.00 \mathrm{E}-02 & 1.18 \mathrm{E}+02 & 1.21 \mathrm{E}+01 \\ 0.1 & 1.00 \mathrm{E}-01 & 3.94 \mathrm{E}-02 & 4.02 \mathrm{E}-03 \\ 0.3 & 1.00 \mathrm{E}-01 & 3.55 \mathrm{E}-01 & 3.62 \mathrm{E}-02 \\ 1 & 1.00 \mathrm{E}-01 & 3.94 \mathrm{E}+00 & 4.02 \mathrm{E}-01 \\ 3 & 1.00 \mathrm{E}-01 & 3.55 \mathrm{E}+01 & 3.62 \mathrm{E}+00 \\ 10 & 1.00 \mathrm{E}-01 & 3.94 \mathrm{E}+02 & 4.02 \mathrm{E}+01\end{array}$

Table 2: Experimental conditions for all experiments. Table 2b indicates the symbol colors in Figures.

$$
\begin{aligned}
& { }^{*}: \phi_{\mathrm{b}}=\text { Volume }_{\text {bubble }} / \text { Volume }_{\text {total }} \\
& { }^{*}: \phi_{\mathrm{p}}=\text { Volume }_{\text {paticle }} /\left(\text { Volume }_{\text {liquid }}+\text { Volume }_{\text {particle }}\right)
\end{aligned}
$$




$\begin{array}{rrrr}\text { Frequency } & \text { Amplitude accerelation a/g } \\ 0.1 & 1.00 \mathrm{E}-03 & 3.94 \mathrm{E}-04 & 4.02 \mathrm{E}-05 \\ 0.3 & 1.00 \mathrm{E}-03 & 3.55 \mathrm{E}-03 & 3.62 \mathrm{E}-04 \\ 1 & 1.00 \mathrm{E}-03 & 3.94 \mathrm{E}-02 & 4.02 \mathrm{E}-03 \\ 3 & 1.00 \mathrm{E}-03 & 3.55 \mathrm{E}-01 & 3.62 \mathrm{E}-02 \\ 10 & 1.00 \mathrm{E}-03 & 3.94 \mathrm{E}+00 & 4.02 \mathrm{E}-01 \\ 0.1 & 3.00 \mathrm{E}-03 & 1.18 \mathrm{E}-03 & 1.21 \mathrm{E}-04 \\ 0.3 & 3.00 \mathrm{E}-03 & 1.06 \mathrm{E}-02 & 1.09 \mathrm{E}-03 \\ 1 & 3.00 \mathrm{E}-03 & 1.18 \mathrm{E}-01 & 1.21 \mathrm{E}-02 \\ 3 & 3.00 \mathrm{E}-03 & 1.06 \mathrm{E}+00 & 1.09 \mathrm{E}-01 \\ 10 & 3.00 \mathrm{E}-03 & 1.18 \mathrm{E}+01 & 1.21 \mathrm{E}+00 \\ 0.1 & 1.00 \mathrm{E}-02 & 3.94 \mathrm{E}-03 & 4.02 \mathrm{E}-04 \\ 0.3 & 1.00 \mathrm{E}-02 & 3.55 \mathrm{E}-02 & 3.62 \mathrm{E}-03 \\ 1 & 1.00 \mathrm{E}-02 & 3.94 \mathrm{E}-01 & 4.02 \mathrm{E}-02 \\ 3 & 1.00 \mathrm{E}-02 & 3.55 \mathrm{E}+00 & 3.62 \mathrm{E}-01 \\ 10 & 1.00 \mathrm{E}-02 & 3.94 \mathrm{E}+01 & 4.02 \mathrm{E}+00 \\ 0.1 & 3.00 \mathrm{E}-02 & 1.18 \mathrm{E}-02 & 1.21 \mathrm{E}-03 \\ 0.3 & 3.00 \mathrm{E}-02 & 1.06 \mathrm{E}-01 & 1.09 \mathrm{E}-02 \\ 1 & 3.00 \mathrm{E}-02 & 1.18 \mathrm{E}+00 & 1.21 \mathrm{E}-01 \\ 3 & 3.00 \mathrm{E}-02 & 1.06 \mathrm{E}+01 & 1.09 \mathrm{E}+00 \\ 10 & 3.00 \mathrm{E}-02 & 1.18 \mathrm{E}+02 & 1.21 \mathrm{E}+01 \\ 0.1 & 1.00 \mathrm{E}-01 & 3.94 \mathrm{E}-02 & 4.02 \mathrm{E}-03 \\ 0.3 & 1.00 \mathrm{E}-01 & 3.55 \mathrm{E}-01 & 3.62 \mathrm{E}-02 \\ 1 & 1.00 \mathrm{E}-01 & 3.94 \mathrm{E}+00 & 4.02 \mathrm{E}-01 \\ 3 & 1.00 \mathrm{E}-01 & 3.55 \mathrm{E}+01 & 3.62 \mathrm{E}+00 \\ 10 & 1.00 \mathrm{E}-01 & 3.94 \mathrm{E}+02 & 4.02 \mathrm{E}+01\end{array}$

Table 3: Experimental conditions for specific experiments. 
Figure 1: A schematic diagram of the experimental apparatus. A fluid tank with width $l$ above a shaking table is horizontally oscillated with a time $(t)$ dependent displacement of $A \sin (\omega t)$. Oscillations generate the surface undulation $\zeta$. We call $\zeta$ as sway amplitude.

Figure 2: Experimental conditions. (a) Imposed frequencies and fluid layer thickness for one-layer experiments and lower layer thickness for two layer experiments. Different symbols indicate the fluid layer types, cross is liquid one layer, circle is one layer of foam without particles, diamond is one layer of foam with particles, triangle is a foam layer without particles overlies a liquid layer, and star is a foam layer with particles overlies a liquid layer. The color of the symbols represents the liquid viscosity. For two layer experiments, the color of the symbols represent the viscosity of lower layer (Table $2 \mathrm{~b}$ ). Symbol size is proportional to the amplitude of the imposed displacement; smaller symbols indicate the smaller $A$. (b) Foam conditions. $\mathrm{X}$-axis indicates the liquid viscosity of the foam and Y-axis indicates the volume fraction of bubbles in the foam. Color and shape of symbol are the same as those for (a). Size of symbol indicates the bubble size in the foam; larger symbols indicate larger bubbles. Filled symbols indicate that the foam volume decreases after shaking.

Figure 3: Digital photographs of a liquid layer in a sinusoidally oscillating tank $A \sin (2 \pi f t)$ with various displacement amplitudes, $A$ and frequencies, $f$. Photographs are taken after 10 seconds of oscillation and when the left side surface becomes maximum height. Green region is the liquid with viscosity of $1 \mathrm{~Pa} \mathrm{~s}$ whose initial thickness is $0.15 \mathrm{~m}$. The resonance frequency calculated by Eq.(2) is $f_{\mathrm{r}}=1.8 \mathrm{~Hz}$. Images are taken by a video camera off the shaking table with a speed of $30 \mathrm{fps}$.

Figure 4: Same as Figure 3 but showing the dependence on the liquid viscosity and thickness of the liquid layer at $A=30 \mathrm{~mm}$ and $f=2 \mathrm{~Hz}$. Experimental conditions are summarized in Table 3. The resonance frequency of this tank calculated by Eq.(2) for the thin layer experiment is $0.8 \mathrm{~Hz}$, and $f_{\mathrm{r}}=1.7-1.8 \mathrm{~Hz}$ for other experiments. In the thin liquid layer experiment, right side of the image is behind of camera on the shaking table. The liquid with different viscosity is dyed with different colors for visualization. 
Figure 5: (a) Same as Figure 3 but for a foam layer with particles in the sinusoidally oscillating tank with various displacement amplitudes, $A$ and frequencies, $f$. Dark region is the foam whose liquid viscosity is $1 \mathrm{~Pa}$ s and initial thickness is $0.21 \mathrm{~m}$. Experiments are performed in the order of increasing frequencies $f=0.7,0.8,0.9,11.2,1.5,2,2.5,3 \mathrm{~Hz}$ for $A=10 \mathrm{~mm}$, at the same set of frequencies for $A=20 \mathrm{~mm}$, and then $0.5 \leq f \leq 2.7 \mathrm{~Hz}$ with increment of $0.1 \mathrm{~Hz}$ for $A=30 \mathrm{~mm}$. The resonance frequency of this foam layer calculated by Eq.(2) is $f_{\mathrm{r}}=1.8 \mathrm{~Hz}$. (b) Time evolution of the surface height within the range of white lines in (a) for the experiments with $A=30 \mathrm{~mm}$ and a time span of 4.3 minutes. Time increases to the right. X-axis labels indicate imposed frequencies. Oscillation is imposed during 10 seconds at each frequency. Vertical lines indicate the quiescent time. The vertical fluctuations include both spatial and temporal changes, because the original images for this picture are taken from a fixed camera on the ground.

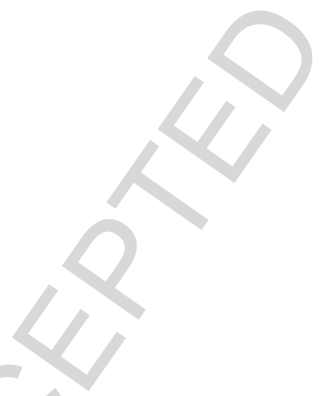

Figure 6: (a) Same as Figure 5a but for a two-layer system. Experimental conditions are summarized in Table 3c. We first shake two layers: an upper foam layer with particles and a lower liquid layer (a1-a4, b1). After the collapse of the upper foam, we shake the tank again with the same set of amplitude and frequency oscillations (a5-a8,b2). The reddish violet region is the foam whose liquid viscosity is $10 \mathrm{~Pa} \mathrm{~s}$ and initial thickness is $0.07 \mathrm{~m}$. The green region indicates the liquid layer whose viscosity is $1 \mathrm{~Pa}$ s and initial thickness is $0.17 \mathrm{~m}$. Amplitude and frequency of oscillation are changed as labeled in (b). The resonance frequency of the lower liquid layer calculated by Eq. (2) is $f_{\mathrm{r}}=1.8 \mathrm{~Hz}$. (b) Same as Figure $5 \mathrm{~b}$ but for Figure $6 \mathrm{a}$ : time evolution of the horizontally averaged interface within the range of white lines in (a) for a time span of 6.6 minutes. (b1) shows the collapse of the foam by shaking and (b2) shows the oscillations of the liquid layer after the collapse of the upper foam layer. 
Figure 7: Flow velocity of Figure 6a1-a8 calculated by the image correlation method. Images are taken from the camera on the shaking table at low angle with a frame rate of 240 per second, so that the downward interface between the liquid/foam or liquid/air is observed as shown in the original images at the left. White boxes on the images show the region in which velocity is calculated. Arrows indicate the flow direction and color shows the velocity. The calculated slow velocity in gray region sometimes does not show the real flow velocity (see text). The intensity difference in gray region indicates the original still images. The interface between the foam and liquid layer is traced manually for reference but it has width as shown in the original images at the left.

Figure 8: Measured maximum sway amplitudes of liquid layer experiments for each condition as a function of the imposed frequency normalized by resonance frequency. The resonance frequency is calculated by using Eq.(2). The color of symbols represent the liquid viscosity (Table 2b). The plus and crosses indicate whether the sway reaches the roof of the tank or not, respectively.

Figure 9: Measured amplitude of the surface wave as a function of the calculated amplitude by Eq.(5). Experiments performed with a liquid layer are denoted by plus and cross, in which plus indicates that the sway reaches the roof of the tank. Other solid symbols are the same as Table 2; circle is one layer of foam without particles, diamond is one layer of foam with particles, triangle is foam layer without particles overlies a liquid layer, and star is foam layer with particles overlies a liquid layer. The color of symbols represents the liquid viscosity. The black line indicates the slope 1 . We plot experiments with frequencies of $f / f_{\mathrm{r}}<1.2$. For one-layer experiments, we do not plot experiments without a top free space.

Figure 10: Regime diagram of the foam collapse as a function of strain and force ratio defined by Eqs.(6) and (10). Solid and open symbols indicate occurrence and no occurrence of foam collapse, respectively. Other characteristics of symbols are the same as Table 2, in which shapes indicate the foam types and color indicates the liquid viscosity of the lower layer. Experiments in which the tank is fully filled with a single foam layer are excluded from this figure. The black line indicates $\mathrm{F}_{\mathrm{i}} / \mathrm{F}_{\mathrm{v}}=\left(\zeta / h_{\mathrm{f}}\right)^{-9 / 4}$. 
Figure 11: Contour curves showing resonance frequencies (in $\mathrm{Hz}$ ) of magma reservoirs as a function of its height $h$ and width $l$ calculated by Eq.(2). Pink to blue region indicates the higher to lower frequency range of seismic waves possibly excited by smaller and larger earthquakes, respectively. Ordinal seismic waves $>1 \mathrm{~Hz}$ do not resonate with conduits or dikes wider than $>0.5 \mathrm{~m}$, suggesting that only large earthquakes can cause sloshing. The red dashed line indicates $h \sim l$. Green region indicates the dimensions of magma reservoirs.

Figure 12: Calculated sway amplitudes by Eq.(5) in a magma reservoir with a condition of $l \sim \lambda / 2 \sim h$ as a function of the ground velocity $v_{\mathrm{g}}=A \omega$. A foam layer thinner than $\zeta$ can collapse. The line color and thickness indicate the viscosity and conduit width, respectively. The resonance frequency is calculated by Eq.(2) and $l=1 \mathrm{~m}: 0.9 \mathrm{~Hz}, l=10 \mathrm{~m}: 0.3 \mathrm{~Hz}$, $l=100 \mathrm{~m}: 0.09 \mathrm{~Hz}$ for each conduit width.

Figure 13: Contour lines of $\mathrm{F}_{\mathrm{i}} / \mathrm{F}_{\mathrm{v}}=1$ calculated by Eq.(10). Above each line, foams can collapse by oscillation of the magma reservoirs. Line color indicates the melt viscosity of the foam. The line type shows the bubble fraction; solid and dotted line indicates $\phi_{\mathrm{b}}=0.6$ and $\phi_{\mathrm{b}}=0.8$, respectively. The black lines are references for a bubble radius of $R \sim 10^{-3} \mathrm{~m}$, and a seismic wave velocity of $1 \mathrm{~m} \mathrm{~s}^{-1}$, respectively.

Figure 14: A flow chart of a magma reservoir oscillation. When seismic waves strongly shake a magma reservoir which has a space above a magma foam or have a density stratification, sloshing can occur. If the energy supplied by the seismic waves is sufficiently large, the foam collapses. The foam collapse releases volcanic gas, which results in unusual degassing. The collapsed foam mixes with the underlying fresh magma layer to prepare following eruption. 
Figure 15: (a) Schematic diagram of possible settings before the 1707 Mt. Fuji eruption. We consider that high temperature basaltic magma with viscosity of $1 \mathrm{~Pa}$ s locates beneath a dacite magma foam with a bubble volume fraction of 0.8 in a reservoir whose width is $l=1 \mathrm{~km}$. Resonance frequency of the magma reservoir calculated by Eq.(2) is $0.03 \mathrm{~Hz}$. (b) Foam collapse conditions, when a seismic wave with a displacement amplitude of $A=1 \mathrm{~m}$ oscillates this reservoir as a function of foam thickness and bubble radius. The color shows the liquid viscosity of the upper layer foam.

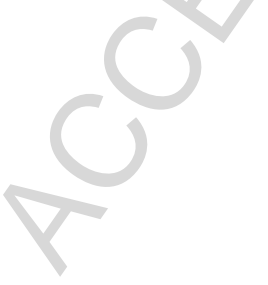


Figure 1

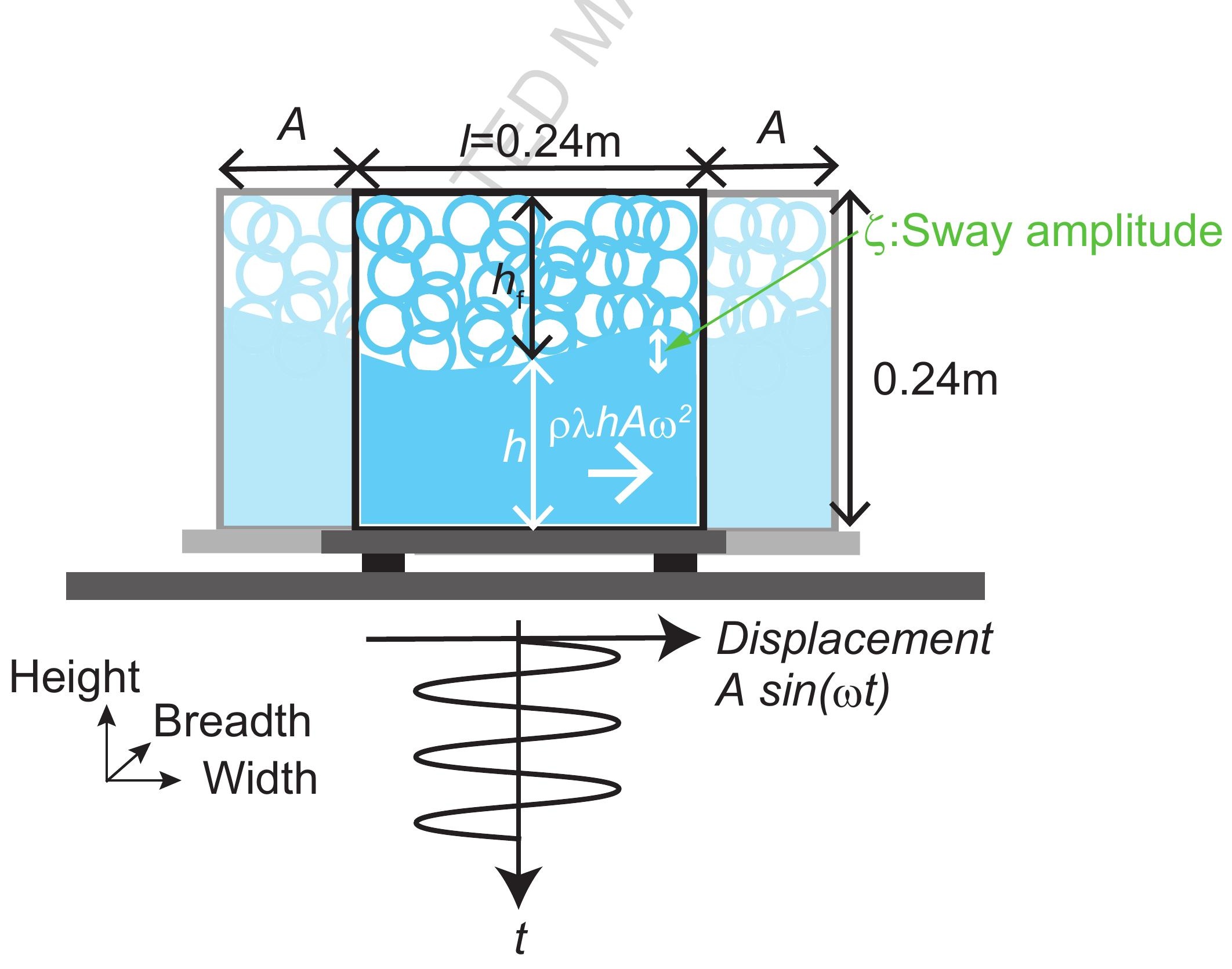

Height
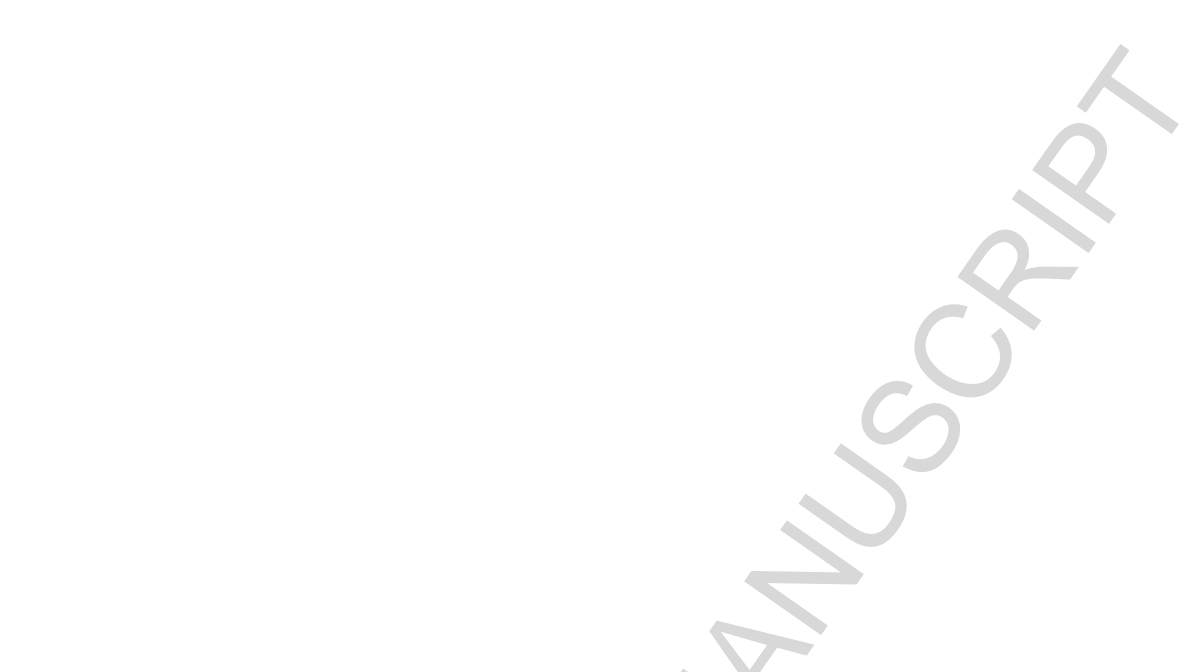

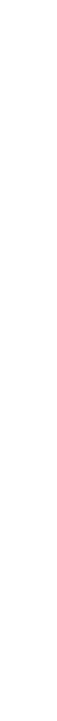


Figure 2
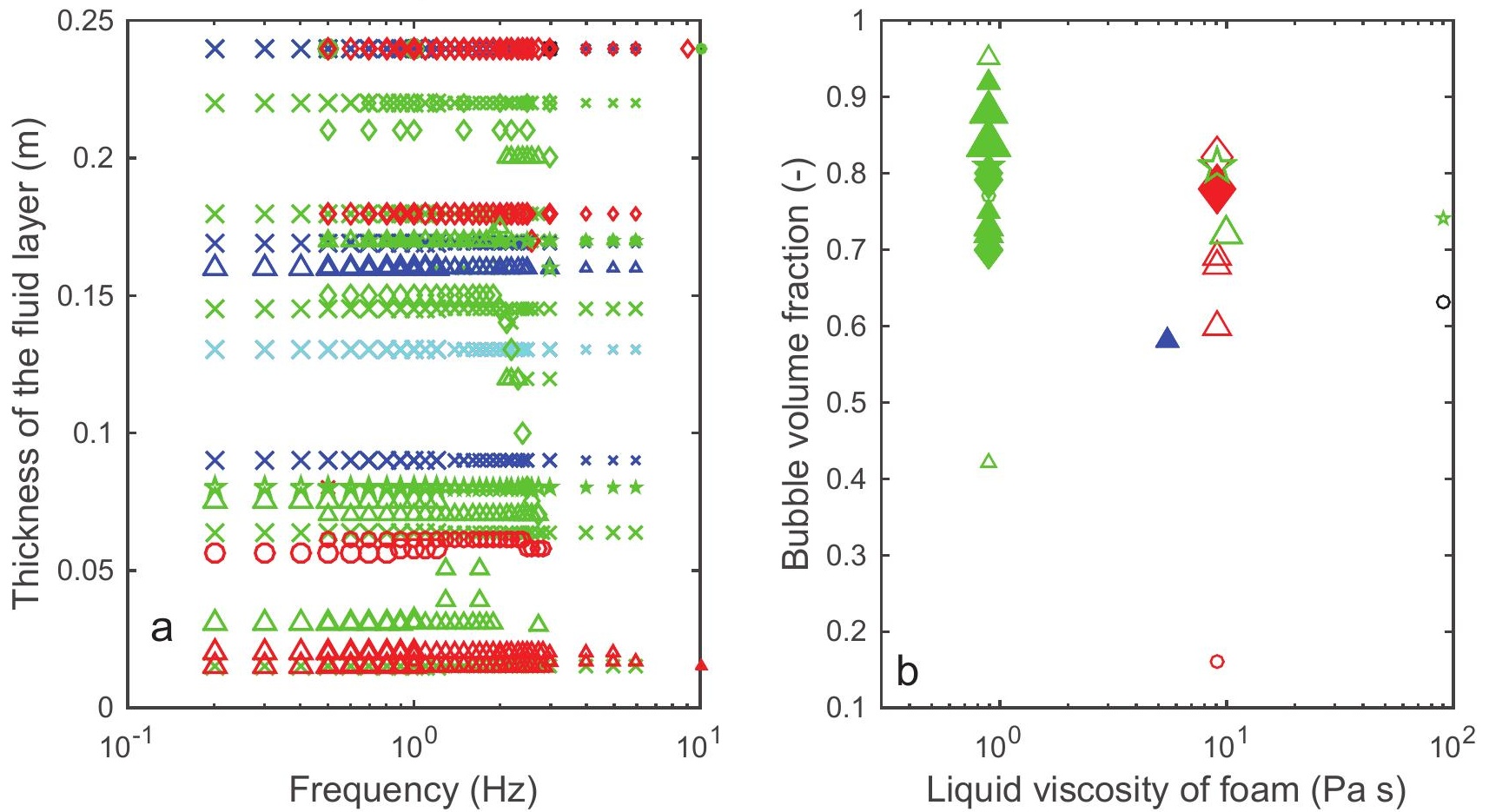
$\mathrm{A}=5 \mathrm{~mm}$

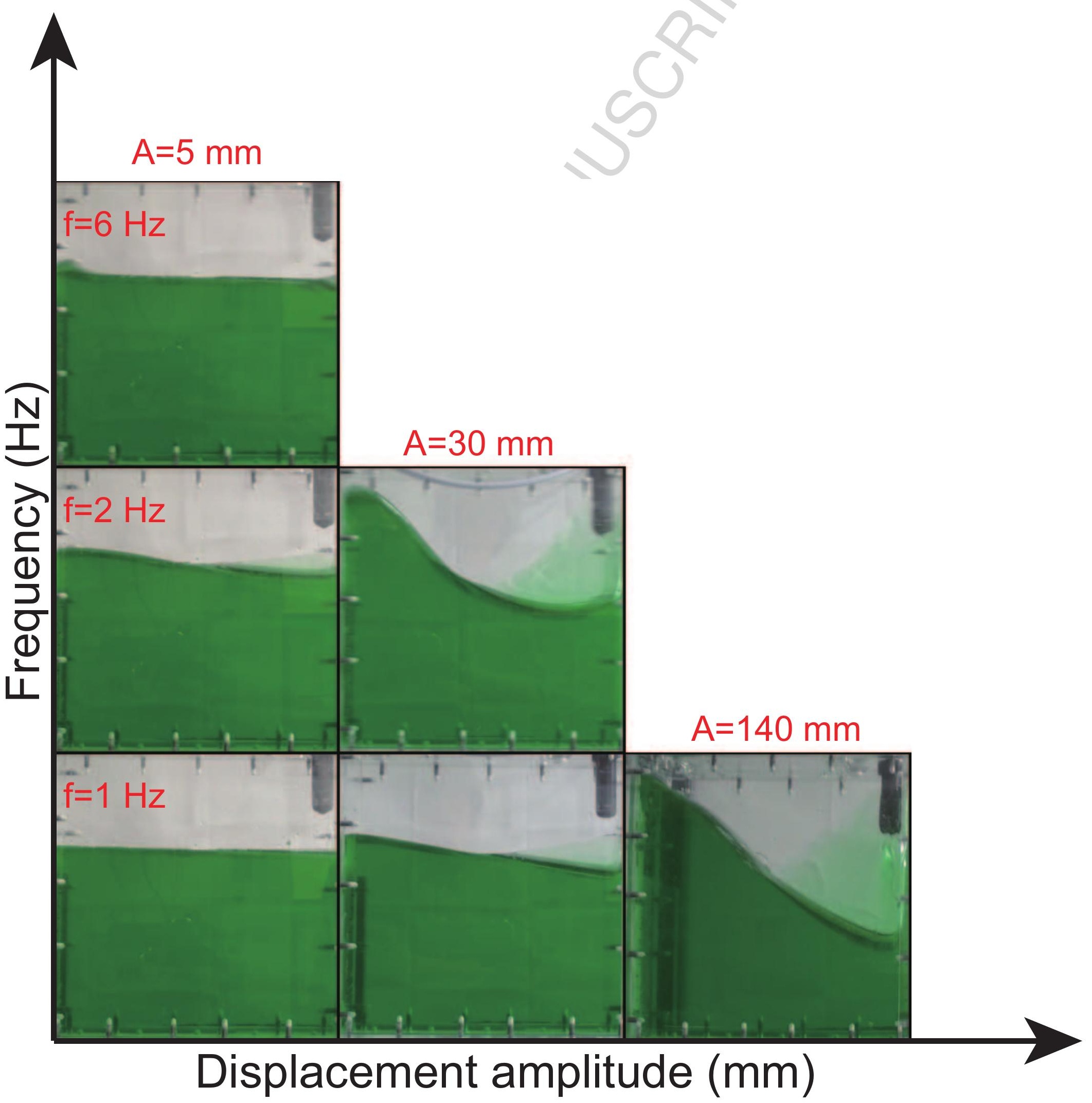

Figure 3

\section{$\mathrm{A}=140 \mathrm{~mm}$}

\section{Displacement amplitude (mm)}




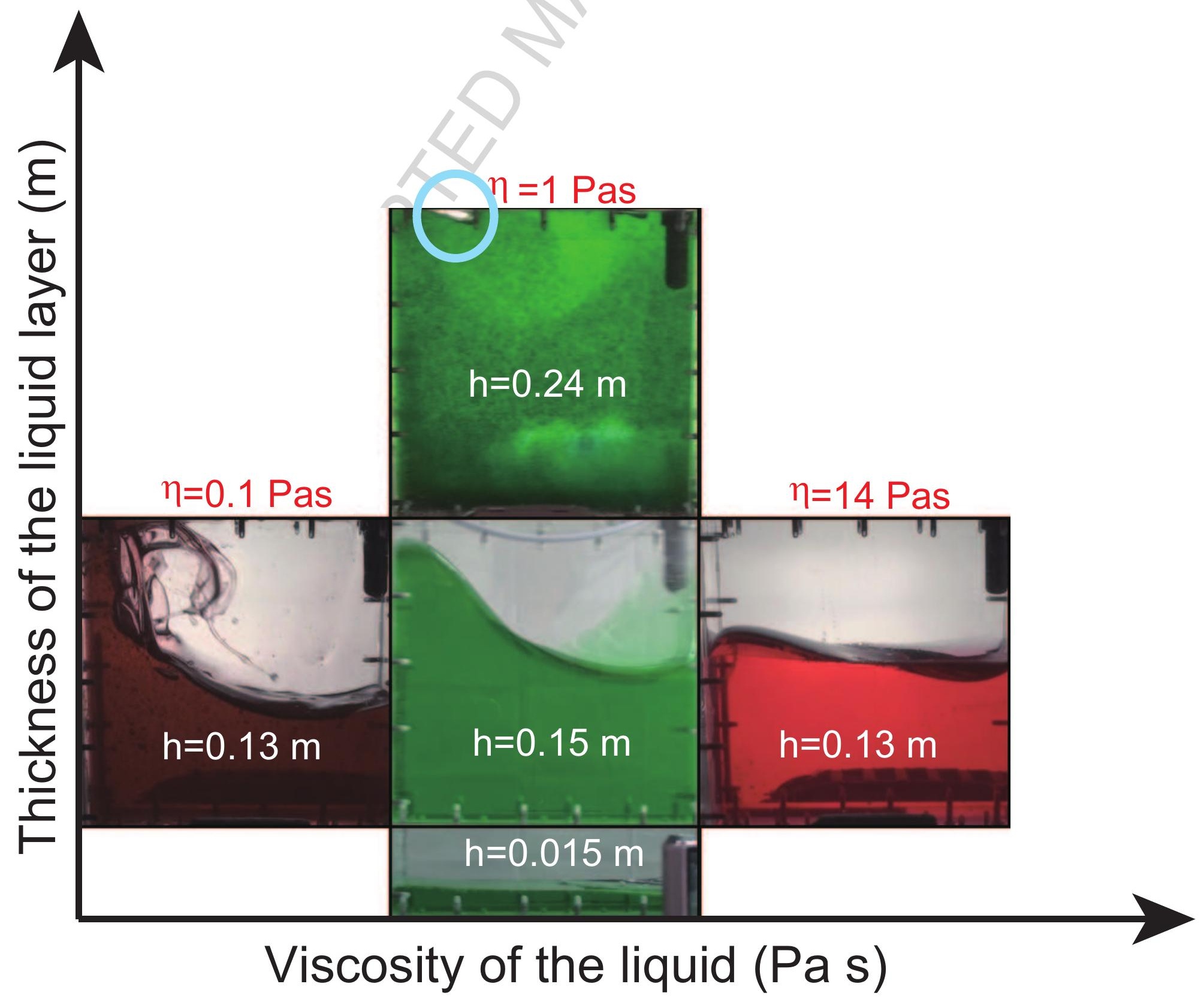




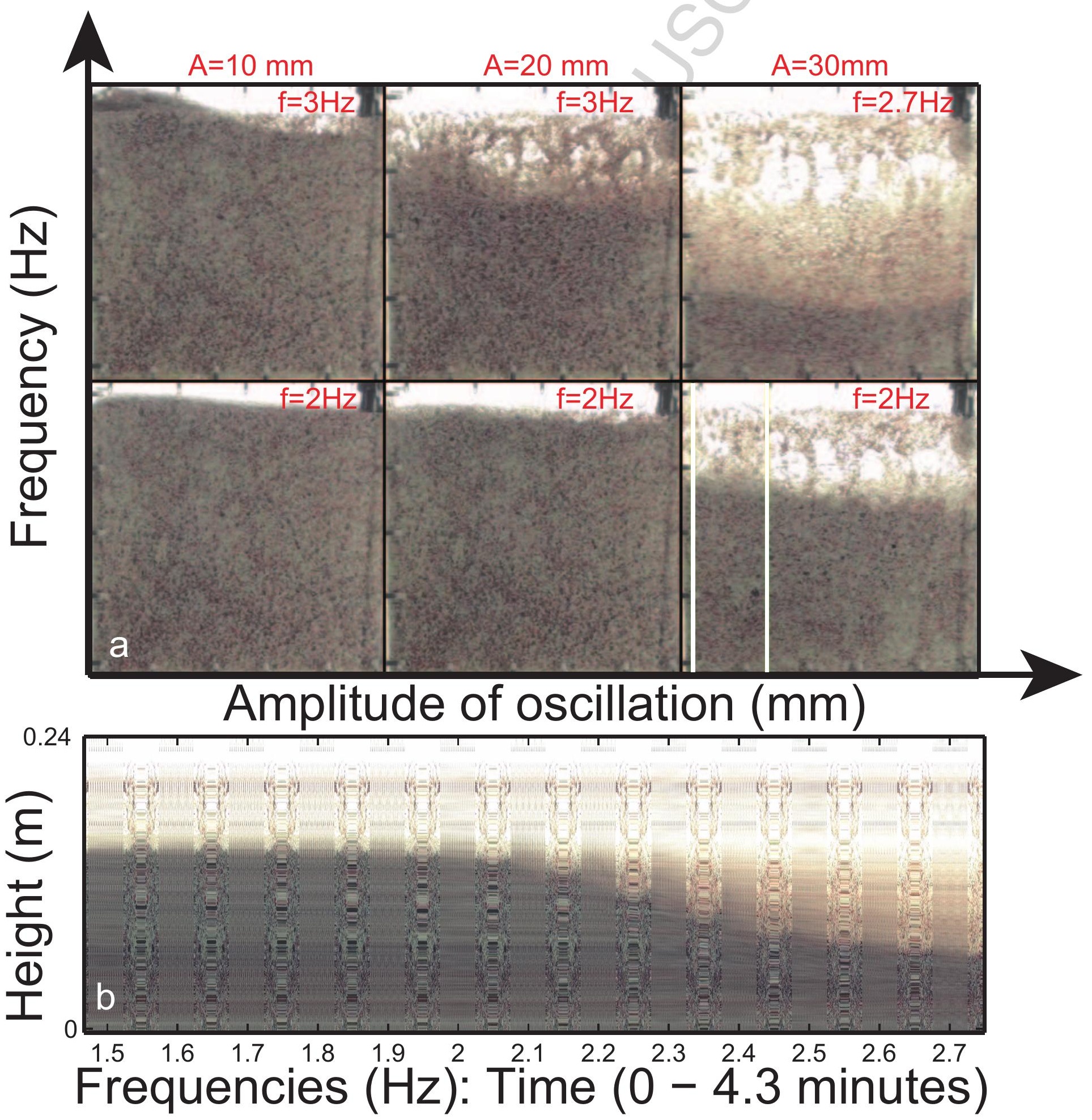


$A=3 \mathrm{~mm}, f=2 \mathrm{~Hz}: A=10 \mathrm{~mm}, f=2 \mathrm{~Hz}: A=20 \mathrm{~mm}, f=2 \mathrm{~Hz}: A=20 \mathrm{~mm}, f=3 \mathrm{~Hz}$

Figure 9

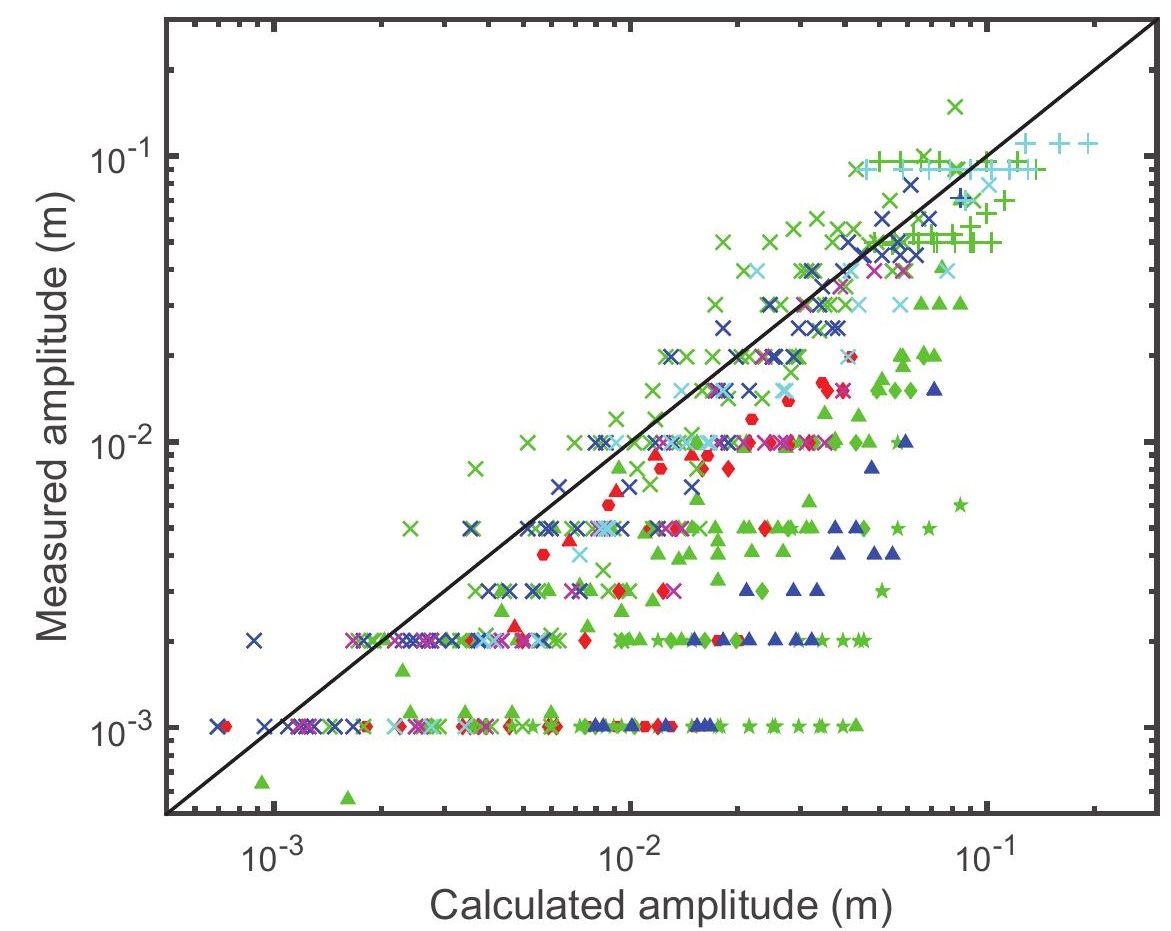


Figure 10

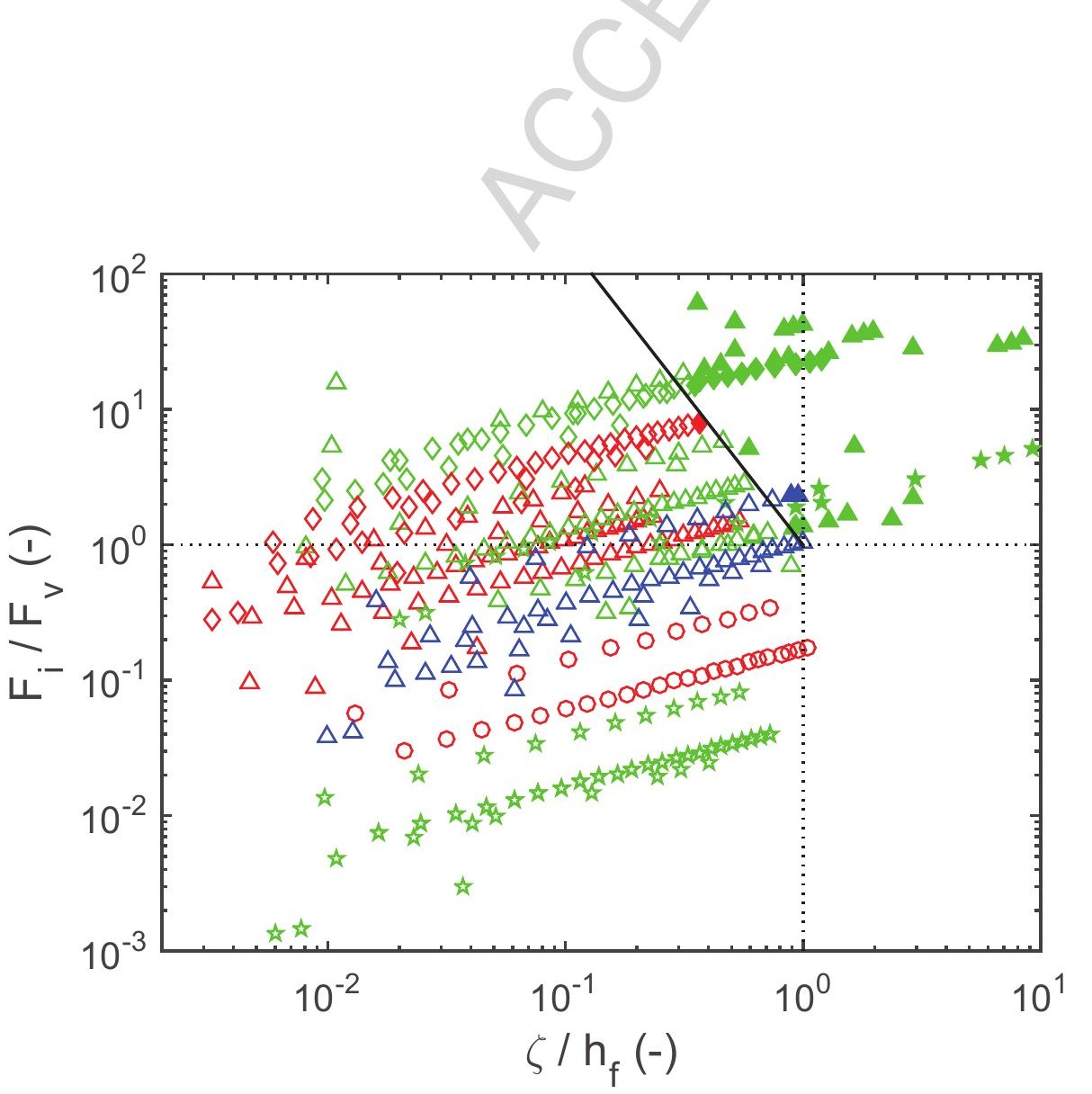




\section{0}

$\underline{\underline{E}}$

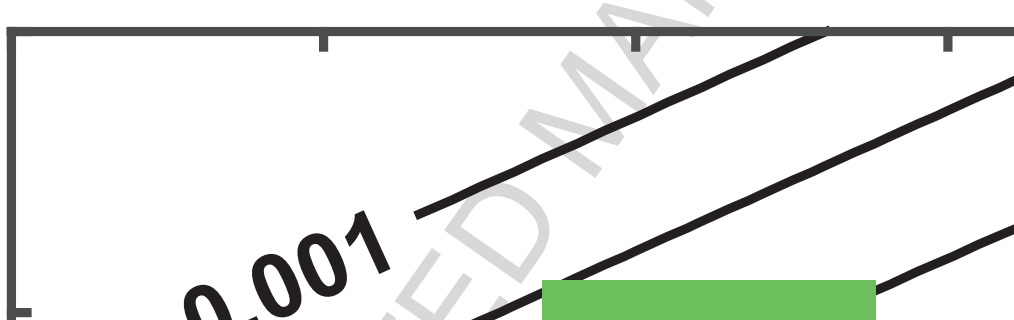

Equidimensional

1000

100

10

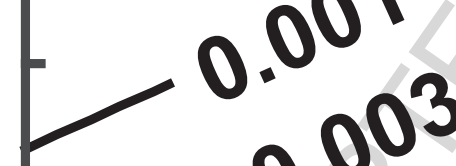

$0.00^{3}$ - Sills

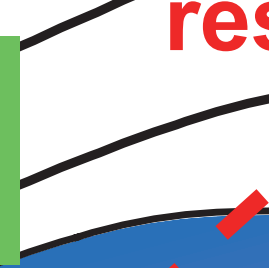
reservoir 0.0

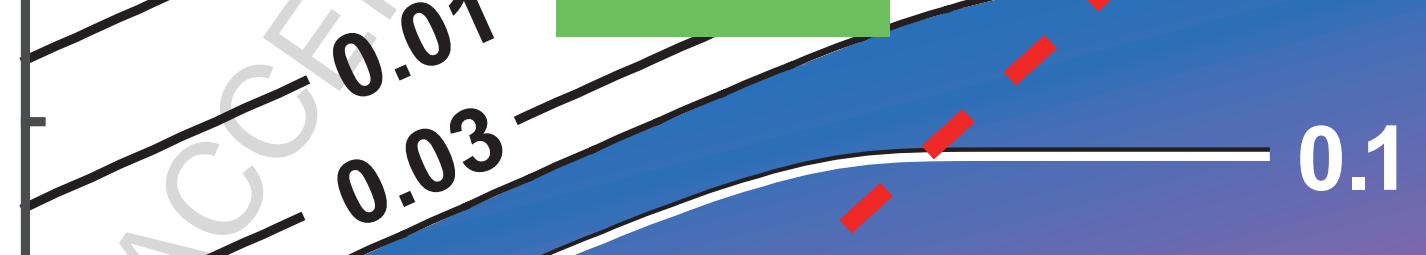

1

0.3

Volcanic conduits

$-1$

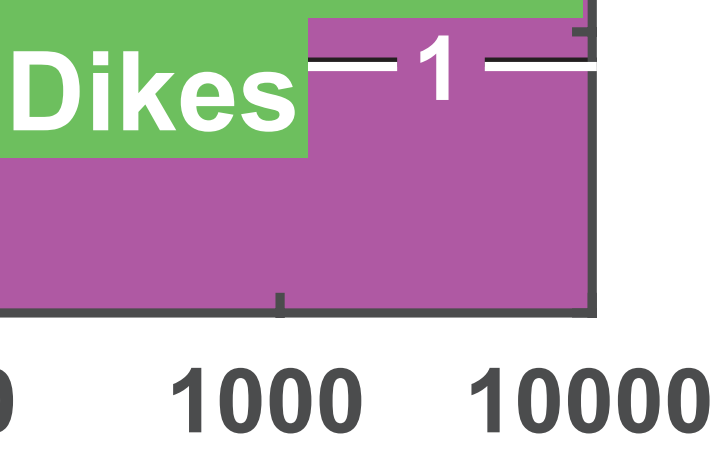

$h(\mathrm{~m})$ 
Figure 12

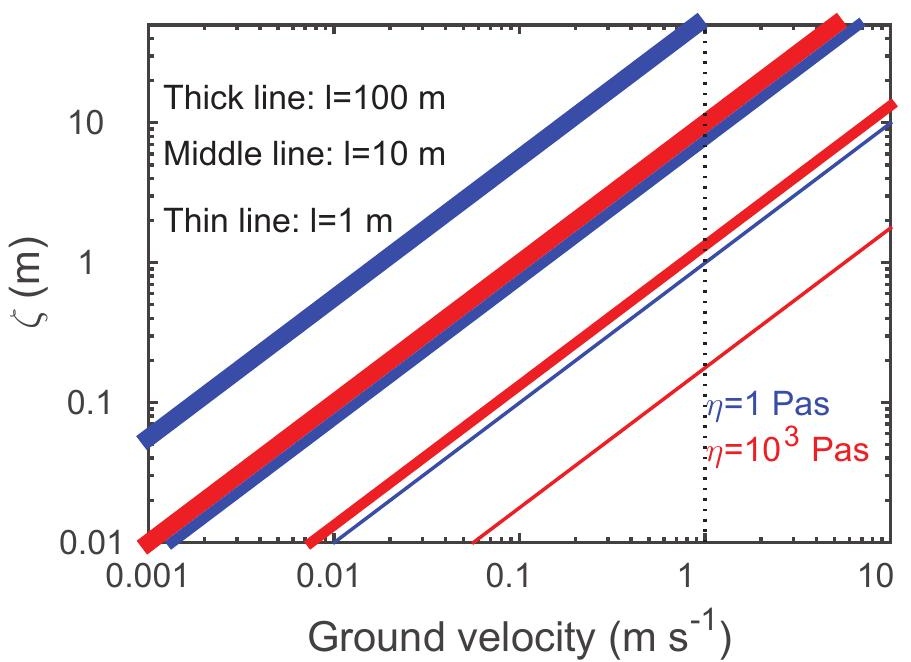


Figure 13
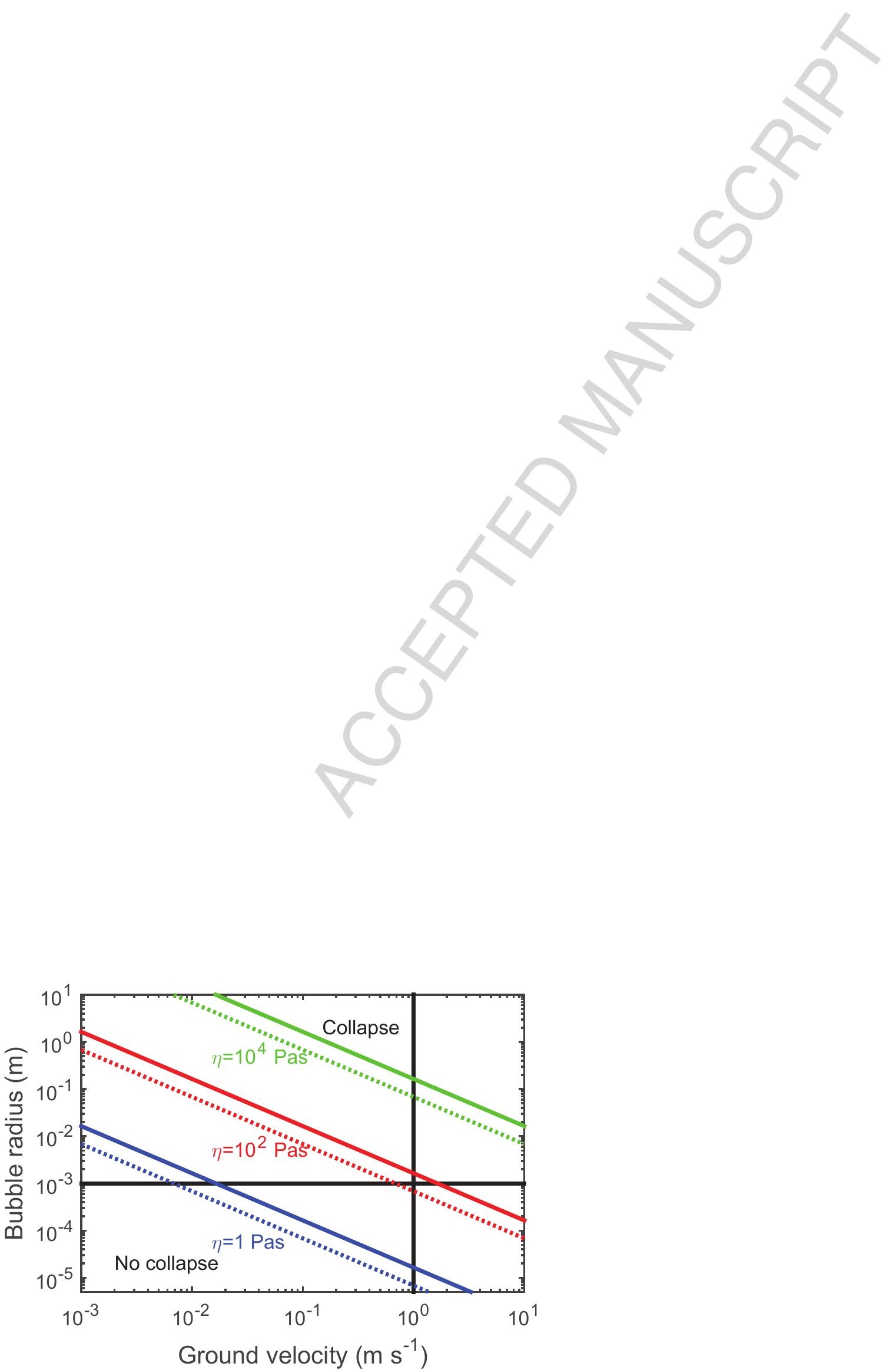


\section{Graphical Abstract}

The shape of the chamber/conduit determines the resonance frequency
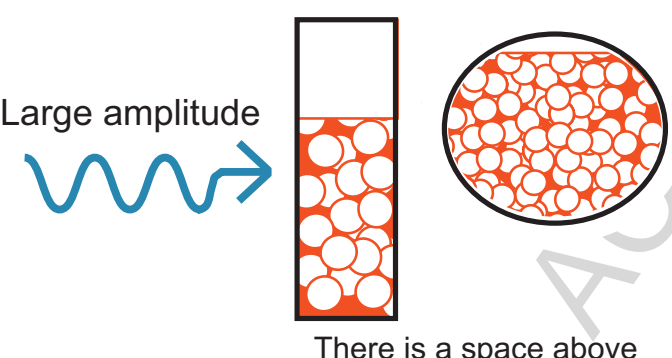

a foam layer

(chamber/conduit)
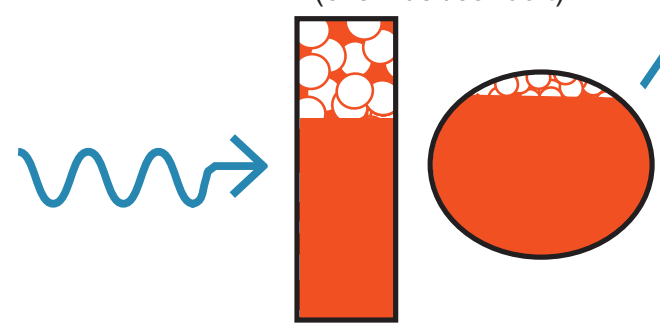

A foam layer overlies a dense melt layer in a chamber or conduit.

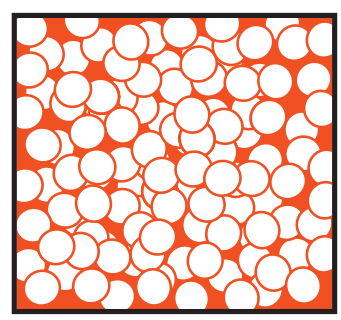

A foam or magma fills a chamber or a conduit. $\zeta / h_{f}>1$ (Eq.6); i.e., the seismic wave is at a resonance frequency with a large ground velocity. The viscosity of the oscillating layer is low. Foam layer is thin.

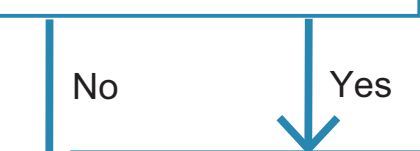
$\mathrm{F}_{\mathrm{i}} / \mathrm{F}_{\mathrm{v}}>1$ (Eq.10); i.e., foam includes large bubbles surrounded by low viscosity melts, and has large bubble fraction.

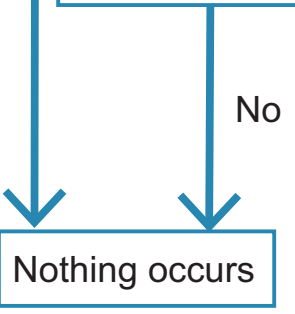

Gas emission through cracks. Strombolian eruption?

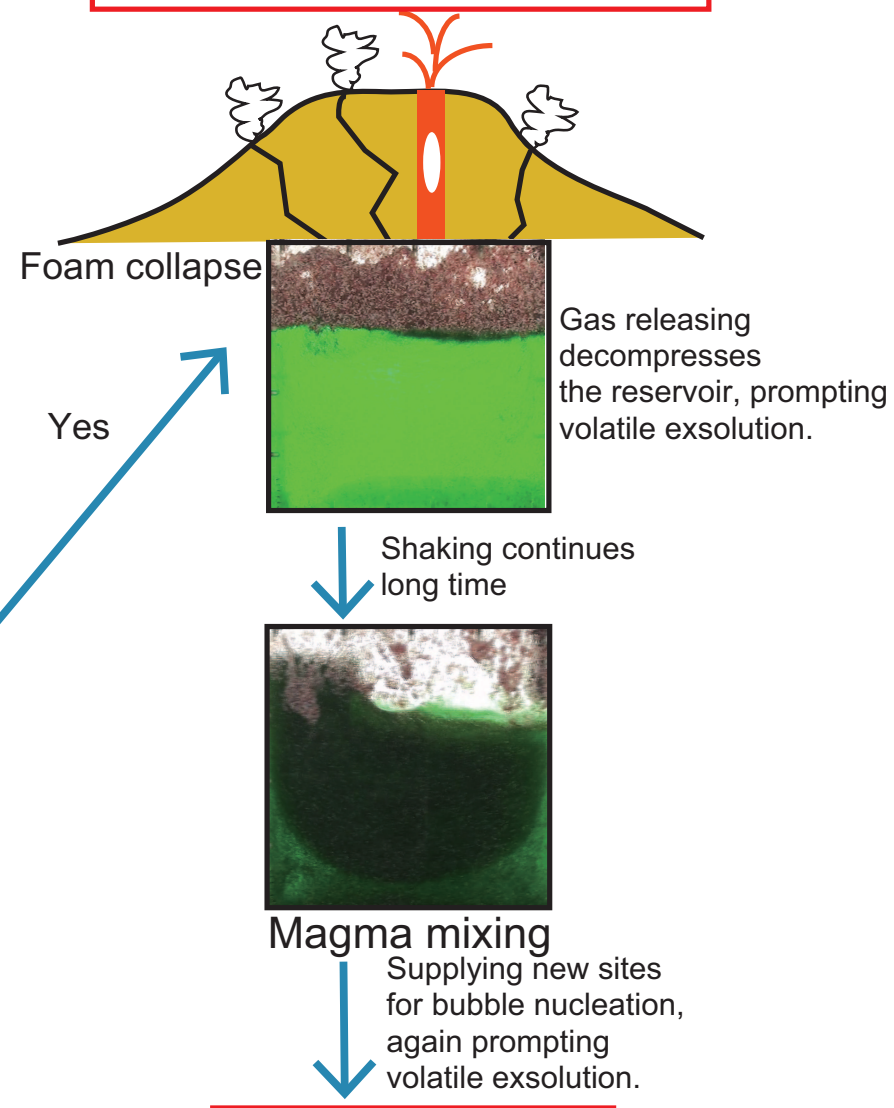

Delayed triggered eruption? 


\section{Highlights}

- We conducted sloshing experiments by shaking viscous foams as a magma analogue.

- Foam collapse occurs by sloshing when the fluid layer resonates.

- Thinner foam layers in a less viscous melt with larger bubbles easily collapse.

- Sloshing can mix the collapsed magma foam with an underlying dense melt layer.

- Magma mixing during Hoei eruption of Mt. Fuji might be explained by sloshing. 